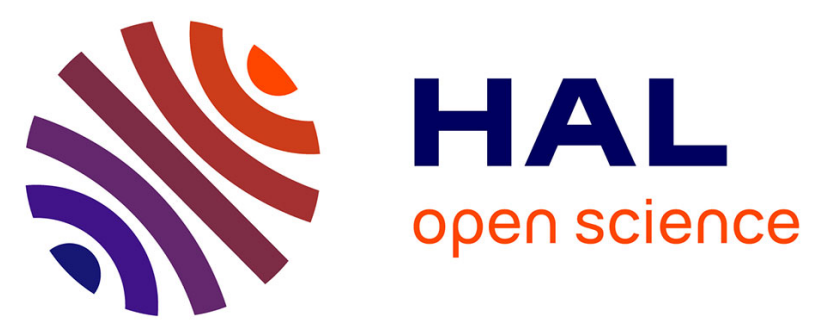

\title{
Intense and small freshwater pools from rainfall investigated during SPURS-2 on November 92017 in the eastern tropical Pacific
}

Gilles Reverdin, Alexandre Supply, Kyla Drushka, E. J. Thompson, William E. Asher, Antonio Lourenço

\section{To cite this version:}

Gilles Reverdin, Alexandre Supply, Kyla Drushka, E. J. Thompson, William E. Asher, et al.. Intense and small freshwater pools from rainfall investigated during SPURS-2 on November 92017 in the eastern tropical Pacific. Journal of Geophysical Research. Oceans, 2020, 125 (2), pp.e2019JC015558. 10.1029/2019JC015558. hal-02468826

\section{HAL Id: hal-02468826 \\ https://hal.sorbonne-universite.fr/hal-02468826}

Submitted on 6 Feb 2020

HAL is a multi-disciplinary open access archive for the deposit and dissemination of scientific research documents, whether they are published or not. The documents may come from teaching and research institutions in France or abroad, or from public or private research centers.
L'archive ouverte pluridisciplinaire HAL, est destinée au dépôt et à la diffusion de documents scientifiques de niveau recherche, publiés ou non, émanant des établissements d'enseignement et de recherche français ou étrangers, des laboratoires publics ou privés. 
Intense and small freshwater pools from rainfall investigated during SPURS-2 on November 9 2017 in the eastern tropical Pacific.

G. Reverdin ${ }^{1}$, A. Supply ${ }^{1}$, K. Drushka ${ }^{2}$, E. J. Thompson ${ }^{2,3}$, W. E. Asher ${ }^{2}$, A. Lourenço ${ }^{1}$

${ }^{1}$ Sorbonne Université, CNRS-IRD-MNHN, Laboratoire d'Océanographie et du Climat : Expérimentation et Approches Numériques (LOCEAN), Paris, France

${ }^{2}$ Applied Physics Laboratory, University of Washington, Seattle, WA, USA

${ }^{3}$ NOAA Earth System Research Lab, Boulder, CO, USA

Corresponding author: Gilles Reverdin gilles.reverdin@locean-ipsl.upmc.fr ORCID ID https://orcid.org/0000-0002-5583-8236

Submitted to JGR oceans 08/08/2019 
$\underline{\text { Headings of the key sections }}$

1. Introduction

2. Data

2.1 Drifters

2.2 SSP

2.3 Meteorological Measurements

3. Measurements

3.1 Meteorological records

3.2 Near-surface temperature and salinity

3.3 Vertical stratification

4. Discussion

5. Conclusion 
$\underline{\text { Abstract }}$ 
1 During the SPURS-2 2017 tropical Pacific cruise, two drifters were deployed on November 9.

2 The drifters measured temperature and salinity in the top $36 \mathrm{~cm}$, wave spectra, and the noise

3 of rain drops. During a short nearly-circular survey with a $1.8-\mathrm{km}$ radius around the drifters,

4 the R/V Revelle measured air-sea fluxes, as well as temperature and salinity stratification in

5 the top $1 \mathrm{~m}$ from a towed surface salinity profiler (SSP). A C-band weather radar measuring

6 rain rate within 1 to $100 \mathrm{~km}$ range of the ship observed discrete rain cells organized in a

7 system moving from the southeast to the northwest. Some of the intense rain cells were small-

8 scale $(1 \mathrm{~km}$ in diameter or less) with short lifetimes, yet dropped more than $5 \mathrm{~cm}$ of water in

9 half an hour near the drifters, whereas the ship measured short rain episodes totaling $1.3 \mathrm{~cm}$ of rainfall mostly accompanied by very low wind. The data indicate a large spatial heterogeneity in temperature and salinity, with near-surface freshening of up to 9 psu measured at different times by the two drifters (separated by less than $500 \mathrm{~m}$ ) and by the SSP. The drifters indicate

13 deepening of the fresh and cool surface layer during the rain which then thinned during the 14 following 40 minutes with very low wind speed $(<2 \mathrm{~m} / \mathrm{s})$. Patchy surface-trapped cold and 15 fresh layers were also observed by the SSP east of the drifters. The high spatial and temporal variability of rainfall and surface-trapped fresh pools is discussed. 
19 We present data illustrating remarkably low surface salinity for the open ocean, outside of the high latitudes near the sea ice or of river plumes. This event was observed by two instrumented drifters and a towed instrument during the R/V Revelle SPURS-2 2017 cruise near $10^{\circ} \mathrm{N} / 125^{\circ} \mathrm{W}$ on November 92017 . The large surface-trapped fresh and cold signal was

23 observed for up to an hour after the rain, and was associated with low to very low surface

24 wind. The data illustrate a large patchiness of the fresh and cold surface pool induced by intense but short lived rain events, at spatial scales of $1 \mathrm{~km}$ or less. Radar and ship meteorological data also illustrate a large spatial variability of the total rain accumulation, which in some places, such as near the drifters, exceeded $5 \mathrm{~cm}$, whereas it was barely $1 \mathrm{~cm}, 1$ or $2 \mathrm{~km}$ away. An estimate of the fresh layer thickness suggests that the fresh surface layer was up to $30 \mathrm{~cm}$ thick under the most intense rain, but shallowed afterwards to be on the order of $20 \mathrm{~cm}$. 
1. Introduction

The second Salinity Processes in the Upper Ocean Regional Study (SPURS-2) project is aimed at understanding the impact of rain on surface salinity, upper ocean stratification and circulation in the ITCZ of the near-equatorial Pacific Ocean (near $10^{\circ} \mathrm{N}, 125^{\circ} \mathrm{W}$ ). The scales investigated range from the time-scale of a rain event of a few minutes duration to the seasonal time scale; vertical scales of a few $\mathrm{cm}$ to a few tens of meters; and horizontal scales from one to hundreds of kilometers (Lindstrom et al., 2019). Earlier studies have shown a fast local response to rain events, with surface freshening proportional to the rain intensity (Drushka et al., 2016; Bellenger et al., 2017), to a power of the rain intensity (Asher et al., 2014), or to the rain accumulation (ten Doeschate et al., 2019) and inversely proportional to the wind speed (Asher et al., 2014; Drushka et al., 2016; Drushka et al., 2019). The thickness and vertical extent of the initial fresh pool is proportional to the wind speed (Thompson et al. 2019). The strongly-stratified near-surface fresh pools have been shown to often have a short lifetime after the rain (e.g., less than one hour), with a duration dependent on wind intensity (Reverdin et al., 2012; Drushka et al, 2016). In low-wind conditions, fresh pools have been observed to persist for more than 10 hours (Price, 1979; Thompson et al., 2019). Bellenger et al. (2017) also suggested the influence of horizontal spreading of the pools by gravity currents, which have been documented in the tropical oceans (Soloviev and Lukas, 1997; Soloviev et al., 2002) and in numerical model simulations (Soloviev et al., 2015). Horizontal spreading would result in shallower pools and hence increased vertical mixing, particularly with initial conditions of small pools and moderate winds. A temperature cooling signal is usually associated with the rain freshening due to the colder temperatures of raindrops. In addition, heat loss to the atmosphere trapped in the near-surface stratified layers results in more cooling, particularly during night-time rain events (Reverdin et al., 2012; Bellenger et al., 2017).

The observations that have been used to provide information on surface freshening from rain include measurements from drifters (Reverdin et al., 2012; Hormann et al., 2015; Centurioni et al., 2015; Dong et al., 2017; Volkov et al., 2019), profiling floats (ten Doeschate et al., 2019; Drucker and Riser, 2014), surface-following platforms (Asher et al., 2014; Drushka et al., 2019), gliders (Shcherbina et al., 2019), or ships (Soloviev and Lukas 1997, 2006, Wijesekera et al. 1999, Thompson et al. 2019). In most cases, either the local history of rain 
and wind or the spatial extent of the fresh pools and their evolution is not well documented. Recently, at much larger scales (50 to $100 \mathrm{~km}$ ), rain-induced freshening has been investigated from satellite missions with band-L radiometric imagery. Boutin et al. (2016) and Supply et al. $(2018,2019)$ have illustrated that at those scales freshening depends on total rainfall amount but less on large-scale winds (with a weaker response at winds stronger than $6-8 \mathrm{~m} / \mathrm{s}$, Supply et al., 2019). Supply et al. (2018) also documented a short duration (an hour or less) of some of the large freshwater pools. On the other hand, what happens at the $\mathrm{O}(100 \mathrm{~m}$ to $1 \mathrm{~km})$ scales of small rain events in terms of the impacts of wind and rain, and how the small-scale variability integrates to produce the larger scale response, has not been well documented.

Late at night on November 9, 2017 during the SPURS-2 cruise on R/V Revelle, the presence of nearby rain cells was observed to the south-east of the ship by the SEA-POL rain radar on R/V Revelle (Rutledge et al., 2019). The region cut across by the ship (coming from the south) presented little horizontal gradients of surface temperature and salinity and had not experienced any rain in the last 12 hours according to IMERG products (Huffman et al., 2019) with winds of at least $5 \mathrm{~m} / \mathrm{s}$. The deployment site was within a large-scale eastward flow on the order of $0.2 \mathrm{~m} / \mathrm{s}$ according to altimetry and satellite-derived currents from the OSCAR product, and the subsurface currents measured by the ship's VM-ADCP at 17-m depth were to the south-east until 15:30 GMT between 5 and $25 \mathrm{~cm} / \mathrm{s}$.

Two drifter sets were deployed starting at 13:30 GMT, and the ship then did a dedicated survey around them. Here, we use data from the two instrumented drifters and a near-surface salinity profiler (SSP, Drushka et al., 2019) towed by the R/V Revelle to illustrate the rain events and their signature in the ocean. These upper ocean data, along with the rain and wind history, allow investigation of the variability of salinity and temperature in the upper meter of the ocean, both in time (over more than 90 minutes) and partially in space (over the surveyed region of approximately $10 \mathrm{~km}^{2}$ ). We will present the instrumentation, describe the data, and discuss the role that the rain and wind forcing played in generating the observed strong spatiotemporal variability. It is notable that the salinity data shows, to our knowledge, the lowest observed surface salinity in the open ocean. This low surface salinity persisted for at least half an hour after the rain stopped.

\section{Data}

2.1 drifters 
Each drifter set consisted of three individual instrument platforms connected with $8 \mathrm{~m}$ of floating line. The first platform was a SC40 SVP surface drifter (NKE Instrumentation) with a small CARTHE drogue hanging between $\sim 42$ to $\sim 80-\mathrm{cm}$ depth. The second was a CARTHE drifter (PacificGyre) with a drogue between $25 \mathrm{~cm}$ and $63 \mathrm{~cm}$ below the surface (assuming the line is taut and drogue is vertical) (. Novelli and Guigand, 2017).

The third and final platform of the set was a 5-cm thick, drogue-free SURPACT float (Sea Mammal Research Unit [SMRU], University of St Andrews). The package thus responds to a mix of conditions very close to the sea surface (due to the surface elements, in particular the SC40 drifter large surface sphere) down to the deepest part of the drogue near $80 \mathrm{~cm}$ (Fig. 2).

The SC40 drifter has a water temperature probe $20 \mathrm{~cm}$ below the surface, under the spherical surface float. In a previous study of large daily warming events with weak winds (Reverdin et al., 2010), SC40 drifters were found to measure temperature at a water depth of $18 \mathrm{~cm}$. The SC40 drifter also has temperature $(\mathrm{T})$ and conductivity $(\mathrm{C})$ probes placed on a frame at $36-\mathrm{cm}$ depth, below the perturbing effect of the surface float, that are used to estimate salinity $(\mathrm{S})$. The T probe at $18 \mathrm{~cm}$ is assumed to have a time sensitivity of at least 1 minute, and this measurement is slightly influenced by the temperature inside the hull (which is seen during the first 20 minutes after deployment when the inside temperature has not yet fully adjusted to sea temperature). As this temperature is likely to vary slowly after the initial adjustment, relative $\mathrm{T}$ variations on short time scales closely portray the changes in the water flowing near the hull. The $\mathrm{T}$ probe at $36 \mathrm{~cm}$ has a time sensitivity on the order of $1 \mathrm{~s}$ and thus can capture much faster fluctuations in T. The SC40 reports data every five minutes (data are averaged over a period of 30 seconds before the transmission time). Drifter positions are measured with a GPS, giving 10-m horizontal accuracy.

The SURPACT float consists of a circular annular disk with a tag at its center. The tag originates from classical SMRU sea mammal tags (Roquet et al., 2011), but has been ballasted to have a lower center of mass. Every 3 seconds, it reports $\mathrm{T}$ and $\mathrm{C}$ (using an inductive sensor) from a Valeport CTD probe that is located under the tag at $4-5 \mathrm{~cm}$ below the water surface, and was calibrated by the manufacturer with uncertainties on $\mathrm{T}$ less than $0.01^{\circ} \mathrm{C}$ and on $\mathrm{S}$ on the order of $0.02 \mathrm{psu}$ in the upper range of salinity observed. Uncertainties in S might be larger at the low salinities (such as $24 \mathrm{psu}$ ), but are not expected 
to exceed $0.1 \mathrm{psu}$, thus less than $1 \%$ of the dynamical range explored. The float has been designed to minimize vertical mixing, and thus the measurements at the C-T sensors depth are likely representative of a layer within the top $10 \mathrm{~cm}$ of the ocean. The location of the CTD probe under the tag also protects it from the largest bubbles. In addition, the tag reports vertical acceleration at $6.15 \mathrm{~Hz}$. Wave spectra are estimated from the vertical component of acceleration by assuming that the SURPACT follows the vertical displacement of the sea surface. This assumption should hold for wave periods between $8 \mathrm{~s}$ and $0.5 \mathrm{~s}$ : at longer periods, the accelerometer is not sensitive enough for the swells, whereas at periods shorter than $0.5 \mathrm{~s}$ there is a strong influence from the float elements (Reverdin et al., 2013). In earlier deployments (Reverdin et al., 2013), the whole spectrum was used to estimate the wind, leading to possible delays of wave spectra with respect to the wind changes. During this deployment, we also witnessed such effects during the early period (before 14:00 GMT), with an unusual accelerometer spectrum with an energy gap centered near $2 \mathrm{~s}$. Thus, as we are particularly interested in fast changes in local winds, we will only consider waves with the shortest periods (near $0.75 \mathrm{~s}$; thus, wavelength close to $50 \mathrm{~cm}$ ), which are expected to be rather responsive to fast changes in local wind. We thus use the energy of $0.75 \mathrm{~s}$ waves as a proxy for wind speed.

Finally, the SURPACT reports sound spectra every 3 seconds recorded by a microphone under a purpose-made cupola on top of the tag. The data are processed in 7 channels ranging from $63 \mathrm{~Hz}$ to $16 \mathrm{kHz}$ by a MSGEQ7 Graphic Equalizer Rain Sensor. In conditions with no wave breaking such as for the record analyzed here, the sound spectra outputs can be used to estimate the rainfall rate, as is done for agricultural use of similar sensors or with other acoustic rain gauges. This was qualitatively tested in laboratory conditions (by the Sea Mammal Research Unit based in St Andrews, Scotland, as well as at LOCEAN). The results are very insensitive to other sources of noise, such as rain on the sea, animal or nearby engine noise, contrary to sub-surface hydrophone measurements (Nystuen and Amitai, 2003). This was also checked during the cruise prior to this deployment with another SURPACT unit attached to an instrumented mooring: the acoustic sensors reported correctly without saturation for rain rates up to $4 \mathrm{~cm} / \mathrm{hr}$. Of the 7 spectral channels, channel $5(2.5 \mathrm{kHz})$ was found to be most sensitive to rain. During the SPURS-2 deployment, channels 4 to $6(1 \mathrm{kHz}$ to $6.25 \mathrm{kHz}$ ) were often saturated, indicating heavier rain. We thus use channel $3(400 \mathrm{~Hz})$, the highest frequency not to saturate. However, this frequency band is also sensitive to wave splash on the cupola. It is questionable that this channel output is linear with respect to rain 
rate, and the power level of the spectra should be interpreted mostly as a scaling of rain rate, with largest uncertainties at rain rates larger than $4 \mathrm{~cm} / \mathrm{hr}$. The cupolas of the two SURPACTs deployed were different, one being less spherical than the other; this difference in shape is expected to have an impact on the response, which was not quantified. All the SURPACT float measurements are time-averaged and reported every $21 \mathrm{~s}$. The wave accelerometer spectrum is further smoothed spectrally and averaged over $63 \mathrm{~s}$ (so that each reported value represents 18 degrees of freedom). To produce vertical profiles, we combine the SURPACT T-S data at 4-cm with the SC40 T-S data at $18-\mathrm{cm}$ and $36-\mathrm{cm}$, subsampling the SURPACT records at the times of the SC40 measurements every 5-minutes.

The two drifter sets were deployed at around 13:10 to 13:13 GMT during westerly winds of 4 $\mathrm{m} / \mathrm{s}$ and were tracked starting at 13:14 GMT (04:56 local time, thus well before sun rise) at $10.51^{\circ} \mathrm{N}, 124.148 \mathrm{~W}$, when they were $312 \mathrm{~m}$ apart (Figure 1). The distance between them never exceeded $500 \mathrm{~m}$ before 15:30 GMT. The largest increase in drifter separation (nearly $100 \mathrm{~m}$ ) is seen during the rain between 14:00 and 14:30 GMT, when the southern drifter ("drifter S") drifted more rapidly in the southeast direction than the northern drifter ("drifter $\mathrm{N}$ "). It is possible that the velocity difference between the drifters is related to different horizontal momentum input by the rain drops or wind gusts in the stratified surface layer between the two drifters, or some divergence of the freshwater near the surface (with more rainfall at drifter $\mathrm{N}$ than $\mathrm{S}$ ), or even a surface gravity current induced by the gradient of freshwater input. Before the wind strengthened at 15:15 GMT, the drifters drifted eastward or south-eastward at an average speed of $15 \mathrm{~cm} / \mathrm{s}$. After 15:15 GMT, it is likely that the drifters started experiencing weak easterly momentum input from the wind, which strengthened after 15:30 GMT; by 15:40 GMT, drifter velocities were close to $0 \mathrm{~cm} / \mathrm{s}$, i.e., speed decreased by $15 \mathrm{~cm} / \mathrm{s}$ after 15:15 GMT.

\subsection{SSP data}

Throughout the drifter deployment, the SSP was towed in the water outside of the ship's wake (90 m slightly starboard) at a speed close to $2 \mathrm{~m} / \mathrm{s}$. The SSP measures T and S at 4 depths using CTDs mounted on its keel at $0.12 \mathrm{~m}, 0.23 \mathrm{~m}, 0.54 \mathrm{~m}$, and $1.1 \mathrm{~m}$ below water line (Drushka et al., 2019; Fig. 2). In addition to the CTDs, water from the surface ( $\sim \mathrm{cm}$ depth) is sampled continuously using a 'sea snake' (a floating device to pump near-surface water and measure near-surface temperature). The T is measured using a SBE 56 sensor mounted 
alongside the 'sea snake' inlet and salinity is measured by a SBE 45 TSG mounted on the SSP (Drushka et al., 2019). Because of the debubbler used for the sea snake TSG, its response time was longer than that of the four keel-mounted CTDs. Furthermore, the sea snake TSG was also lagged in time relative to the CTDs due to the volume in the tubing and debubbler. During periods of weak stratification when the CTDs and TSG should measure the same T and S, we found that the T-S data from the sea snake need to be advanced by $10 \mathrm{~s}$ to optimize the correlation with T-S data from the CTDs. Spikes in salinity due to bubbles were removed from the data, and a 15-s median-filter was applied separately to the $\mathrm{T}$ and $\mathrm{S}$ data of each sensor, which are then reported every second. Remaining noise is present in salinity, in particular for the upper sensors, but at a level which is small compared with the signals investigated.

\subsection{Meteorological measurements}

Meteorological measurements were made aboard the ship and provided by the SPURS-2 community dataset (Clayson et al., 2019). The data selected were always from instruments on the upwind side of the ship. Here we use measurements of wind speed and rain rate, as well as heat flux estimates. These data are available as 1-minute averages (thus $120 \mathrm{~m}$ of ship track). Since the SSP was towed $90 \mathrm{~m}$ aft of the meteorological sensors, we shifted the meteorological data by 45 seconds to collocate them with the SSP data, assuming that the meteorological variability recorded is spatially frozen, and assuming that the wind measurements were made from sensors located forward on the ship.

The SEA-POL dual-polarization C-band Doppler weather radar mounted on the R/V Revelle provided maps of rain rate close to the sea surface every five minutes at distance from the ship of $1 \mathrm{~km}$ to $100 \mathrm{~km}$ (Rutledge et al., 2019a,b). The data were recorded throughout the two minutes after the round 5 minutes times (e.g., 14:00, 14:05 GMT ...). They have been postprocessed and are provided on a $1 \mathrm{~km}$ square grid. Rain estimates within $60^{\circ}$ of the aft direction of the ship were not measured to avoid illuminating the superstructure of the ship.

\section{Observations}

After deploying the drifters, the R/V Revelle traveled northward $1.8 \mathrm{~km}$ from the drifters and then followed a circular track around the drifters at $2 \mathrm{~m} / \mathrm{s}$ towing the SSP. At the ship, rain rates up to $5 \mathrm{~cm} / \mathrm{hr}$ were measured, accompanied by wind speed below $3 \mathrm{~m} / \mathrm{s}$ until 14:50 GMT (Figure 1,3). Heavy rain and weak winds were also measured by the drifters, with weak 
winds persisting until 15:10 GMT. Sustained easterly winds of $4 \mathrm{~m} / \mathrm{s}$ were measured at the ship after 14:50 GMT (Figure 3). The drifters were then recovered at 17:45 GMT (Fig. 1). We will focus on the 90-minute time period between 13:50 and 15:20 GMT, which had high rain rate and low wind at first and then featured higher wind conditions and mixing of the top layer of the ocean (Figure 3).

\subsection{The meteorological records}

We first comment on the meteorological data from the R/V Revelle (Fig. 3a) and on the sound and wave spectra measured by drifters $\mathrm{N}$ and $\mathrm{S}$ (Fig. 3b, 3c). The wind is moderate $(4 \mathrm{~m} / \mathrm{s}$ ) prior to the drifter deployment and quickly decreases to values of 0 to $2 \mathrm{~m} / \mathrm{s}$ between 13:55 and 14:50 GMT. The wind direction is variable, but usually remains westerly. Close to 14:55 GMT a front is crossed, with wind intensity increasing to $5 \mathrm{~m} / \mathrm{s}$ and wind direction shifting to easterly. A larger wind speed increase happened suddenly after 15:30 GMT with a small shift of direction to ENE (not shown). These wind changes are coincident with changes in the power spectra of the vertical accelerometer of the two SURPACTs, a proxy for wave energy. The wave spectra time series show a decrease of the maximum energy in acceleration found near 1.5s at 14:00 GMT (not shown). The 'shorter' wave spectral power (at $0.75 \mathrm{~s}$ ) (proxy of the wind) is very low between 14:00 and 15:00 GMT, thus a slightly different timing than from the ship's wind speed records. For example, the increase in $0.75 \mathrm{~s}$ wave spectral power happens 15 minutes later than the wind speed increase at 14:55. This indicates spatial gradients of the winds on that 1-2 km distance (Fig. 1). There are also noticeable differences between the two SURPACT records (separated by $\sim 400 \mathrm{~m}$ ) on time scales less than 10 minutes. For example, a small peak in 0.75 s wave energy is observed by SURPACT-N around 15:05 that is not witnessed by SURPACT-S, consistent with wind variability on scales of a few hundreds of $\mathrm{m}$.

The ship rainfall record (Fig. 3) indicates an isolated rain event (near 13:30 GMT, when wind is still near $4 \mathrm{~m} / \mathrm{s}$ ), a set of large rain events between 14:00 to 14:30 GMT, often at rates larger than $2 \mathrm{~cm} / \mathrm{hr}$ (and up to $5 \mathrm{~cm} / \mathrm{hr}$ ), and an isolated weaker rain event at 14:32 GMT. The last rain event happens when wind is $<2 \mathrm{~m} / \mathrm{s}$. Throughout the entire $90 \mathrm{~min}$ period, rain intensity varies by more than a factor of two between successive peaks and troughs separated by a few minutes and a few hundred meters. The SURPACT microphone records (lower panels of Fig. 3) indicate a similar overall sequence of rain events, but starting several minutes earlier at 13:48 GMT and persisting for nearly half an hour. If one assumes that the 
acoustic response to rainfall is linear, Fig. 3 suggests a large intermittency in rain, with local minima in rain rate observed by the two SURPACTs around 14:03 and 14:20 GMT. Although wind speed appears somewhat weaker during rain in this event, they are not significantly correlated over this short record.

During the drifter deployment period, the ship's air sea heat flux estimate (without the cooling effect caused by the deposition of colder rain drops) indicated a small loss (on the order of 45 $\mathrm{W} / \mathrm{m}^{2}$, not shown), which would induce a vertically integrated temperature cooling on the order of $0.040{ }^{\circ} \mathrm{C} \mathrm{m} \mathrm{h}^{-1}$ between 13:50 to 15:00 GMT. Because of the short distance separating the drifters from the ship, we tentatively estimate that this might also be the cooling magnitude due to the heat fluxes at the location of the drifters until the wind increases locally at 15:15 GMT.

\subsection{Near-surface temperature and salinity}

On Figure 3, we also plot the near surface $(\sim 5 \mathrm{~cm}$ depth) $\mathrm{T}$ and $\mathrm{S}$ signal measured by the SSP and the two SURPACTs. Before the rain starts, all three platforms show similar values and no vertical stratification. The agreement between the three platforms indicates that, at least in the northern part of the ship's survey, there is no large spatial gradient in salinity or temperature present over horizontal scales of $1-2 \mathrm{~km}$. After the rain begins, all three records show extremely large surface cooling and freshening, all exceeding $1^{\circ} \mathrm{C}$ and $7 \mathrm{psu}$, and with the extremum of $1.3^{\circ} \mathrm{C}$ and 9.5 psu during event B measured by SURPACT-N (the northern SURPACT). The salinity changes also imply significant changes in surface water density, dominated by $\mathrm{S}$ variability (T variability reduces by roughly $5 \%$ the density variability induced by $\mathrm{S}$ changes).

However, the timing of the cooling and freshening observed from the three platforms is different, as shown by the three time series (Fig. 3). Although the two SURPACTs are separated by less than $400 \mathrm{~m}$, they show a remarkable difference in salinity both during the rain (despite appearing to experience relatively similar amounts of rainfall) and afterwards. Until 14:00 GMT (event A shown on the bottom panel of Figure 3 on SURPACT-S), the two SURPACTs show similar evolution of $\mathrm{T}$ and $\mathrm{S}$. However, whereas $\mathrm{T}$ and $\mathrm{S}$ continue to drop on SURPACT-N towards event B at 14:11 GMT, they remain much higher on SURPACT-S. After event B, there is a large regular increase in salinity observed by SURPACT-N, whereas SURPACT-S salinity shows a plateau, followed by a large decrease reached at 15:07 GMT (event C). At 15:05 GMT, high-frequency wave spectral energy (and hence likely wind 
speed) is slightly larger on SURPACT-N compared to SURPACT-S, which might have contributed to the relative difference in salinity tendency between the two floats. This salinity difference could also be attributed to advection of the fresher surface water flushing past drifter SURPACT-S (the drogue extends deeper than the fresh layer). This suggests that advection of freshwater past the buoy might have also happened earlier during the rain event, which could have contributed to the lack of strong relation between salinity changes and the fast rainfall and wind changes. Both SURPACTs then record $\mathrm{T}$ and $\mathrm{S}$ increases as the wind intensifies after 15:10 GMT, mixing away the freshwater deposited by the rain. $\mathrm{T}$ and $\mathrm{S}$ both continued to increase after 15:30 GMT (not shown).

During the 30 to 40 minute period with rainfall, there is no close correspondence between the fluctuations of rainfall or wind with the changes in T or S. However, for drifter SURPACT-S, periods of slightly lower $0.75 \mathrm{~s}$ waves (i.e., wind) appear to coincide with minima in $\mathrm{T}$ and $\mathrm{S}$ (e.g., at 14:00, 14:15, 14:20 GMT). There is also a tendency for peaks in rainfall estimated from the sound record to precede or correspond to local minima in T and S (e.g., at 14:00, 14:25 GMT). This relation between $\mathrm{T}$ and $\mathrm{S}$ and rainfall is also apparent in the SURPACT-N measurements. Following the rain, there are still large oscillations in $\mathrm{T}$ and $\mathrm{S}$ with periods as short as 5 minutes: for example, on SURPACT-S between 14:20 and 14:55 GMT (typical amplitude $0.1^{\circ} \mathrm{C} / 0.7 \mathrm{psu}$ in $\mathrm{T} / \mathrm{S}$ ). These do not seem closely related to changes in wind waves.

As seen on Figure 3, the temperature and salinity records for a particular SURPACT are well correlated at all scales. This can be better visualized on a T-S diagram color-coded as a function of time (Fig. 4). The T- S data tend to be aligned at a given time, but with an increase in slope with time (notice also on fig. 4 how well correlated the changes in density are related at a given time to the changes in salinity). Until $\sim 1$ hour after the rain starts, the slope of the diagram is on the order of $1.5^{\circ} \mathrm{C} / 10 \mathrm{psu}$. This ratio tends to slightly increase in time, particularly after the rain stops and later, when wind-induced mixing results in increasing $\mathrm{T}$ and $\mathrm{S}$. This can be explained by the fact that due to the strong vertical stratification (cf density changes on Fig. 4), heat loss gets trapped in a shallow surface layer, even after the rain stops, resulting in a net decrease of T relative to changes in S (Reverdin et al., 2012; Bellenger et al., 2017). We hypothesize that this effect will be more pronounced in areas with stronger, shallower stratification.

There are also significant differences between the SSP T and S time series and that from the SURPACT. Starting around 14:33 GMT, there are large fluctuations in T and S from the SSP 
not seen by either SURPACT (Figure 3). At this time, the SSP was being towed through a rain-formed fresh pool, though local rain rate measured at the ship was zero at that time, indicating that the rain had fallen earlier. It appears that these fluctuations indicate variability on scales of one hundred meters to a few hundred meters. At the top panel of Fig. 3, we identify and label four fluctuations seen both in $\mathrm{T}$ and $\mathrm{S}$. Note that fluctuation 1 is fairly close to drifter $\mathrm{S}(1 \mathrm{~km})$, but SSP measures $0.6^{\circ} \mathrm{C}$ and 5 psu smaller $\mathrm{T}$ and $\mathrm{S}$ than the SURPACT-S. When looking at a time zoom over the period with fluctuations, we more clearly identify the temporal structures (Fig. 5). Fluctuations 1, 2 and 3 have salinity drops of more than 2 psu, which last more than 90 seconds and thus are close to 200-m wide. Fluctuation 4, which also features salinity drops, presents similar amplitude but appears to be much narrower in time and space ( $50-\mathrm{m}$ wide). There is a tendency for the low $\mathrm{T}$ and low $\mathrm{S}$ periods to happen near lows in the wind, based on the high-frequency wind record of the ship's meteorological station (at least for fluctuations 1, 3 and 4, whereas 2 occurs between a low and a high of the wind speed). Fluctuation 1 is also associated with a weak local rain shower $(0.03 \mathrm{~cm}$ of total rain), but this would cause a salinity drop at most of $0.2 \mathrm{psu}$ at 5 -cm depth: much smaller than the 2 psu drop observed. This suggests that the $\mathrm{S}$ fluctuation was influenced by nearby rainfall in addition to local rainfall.

\subsection{Vertical stratification}

Figure 5b,c show the T and S records at the different depths on the SSP keel in addition to the snake data. There is a very high correspondence between $\mathrm{T}$ and $\mathrm{S}$ at the different levels. These data indicate stratification trapped close to the surface, with little $\mathrm{T}$ or $\mathrm{S}$ changes observed at $54 \mathrm{~cm}$ (except for small decreases observed near filament 1). Even at $23 \mathrm{~cm}$ depth, there are periods between fluctuations 1 and 3 when the fresh and cool signature of the filaments is not observed, indicating that the $23-\mathrm{cm}$ depth sensor is below the near-surface stratification. In other words, stratification is trapped very near the surface at times, but slightly deeper at fluctuations 1 and 3. Starting at fluctuation 4, wind speed increases and $S$ in the upper $15 \mathrm{~cm}$ becomes homogenous, forming in effect a very shallow mixed layer. This homogenous layer then mixes downwards to $23 \mathrm{~cm}$ by 14:54 GMT. Throughout the time series shown in Figure 5, fluctuations are seen at small scales, most obvious in $\mathrm{T}$ (or $\mathrm{S}$ ) at $12 \mathrm{~cm}$ between 14:33 and 14:39, corresponding to a distance between successive local maxima and local minima on the order of $100 \mathrm{~m}$. This length scale is suggestive of oscillatory behavior due to internal gravity waves. Internal wave-like features have been previously observed in stratified near-surface open ocean conditions (Hodges and Fratantoni, 2017; Asher et al., 2019). It is tempting to 
associate those spatial oscillations to the $\mathrm{T}$ and $\mathrm{S}$ time variability (at 5-minutes period) observed on SURPACT- S, which was then less than $1 \mathrm{~km}$ from the SSP to its northnorthwest. This will be further discussed in the discussion section. On the other hand, we do not observe such intense fast oscillations in T and S on the SSP during the rain period (e.g., 13:50 to $14: 30$ GMT) at 12-cm depth or deeper (not shown).

We will now investigate the freshwater and heat content changes (we take a constant heat capacity so that heat content is being proportional to temperature content with an error of less than $2 \%$ in this salinity range). The freshwater content is expressed as the height of excess freshwater (precipitation minus evaporation; however, evaporation over these timescales is very small) that results in the observed salinity decrease with respect to conditions before the rain, taking into account the small change in seawater density. Profiles of the salinity and temperature anomaly are defined by subtracting the $\mathrm{T}$ and $\mathrm{S}$ measured at 13:45 GMT, which occurred during the initial unstratified period.

The anomaly profiles are constructed from the discrete measurements by assuming that the vertical profile varies linearly between successive instrumented depths, until we reach an instrumented depth $\left(\mathrm{z}_{\mathrm{i}}\right)$ with no anomaly. In that case, we first extrapolate linearly the vertical gradient between the previous pair of instrumented depths $\left(\mathrm{z}_{\mathrm{i}-2}\right.$ and $\left.\mathrm{z}_{\mathrm{i}-1}\right)$ until $\mathrm{T} / \mathrm{S}$ reaches the initial value (no anomaly) found at a depth $\mathrm{z}_{0}$. If $\mathrm{z}_{0}$ is shallower than $\mathrm{z}_{\mathrm{i}}$, we adopt that linear profile with no anomaly below $\mathrm{z}_{0}$, whereas if $\mathrm{z}_{0}$ is deeper than $\mathrm{z}_{\mathrm{i}}$, we adopt a steeper linear profile between instrumented depths $\mathrm{Z}_{\mathrm{i}-1}$ and $\mathrm{Z}_{\mathrm{i}}$. If there is still freshening/cooling at the deepest instrumented level, we extend the profile deeper by extrapolating the gradient above it and down to the level of zero anomaly. A running average over 1 minute is then performed on the temperature and salinity anomaly time series at each depth. We assume that $\mathrm{T}$ and $\mathrm{S}$ are well mixed above the uppermost measurement at 5-cm depth, which is supported by laboratory measurements (Ho et al., 2004; Zappa et al., 2009) showing that rain drops mix the upper 5-10 cm of the water column. We also neglect the effect of anomalies in the surface skin layer of thickness of a few mm (Yu, 2010; Wurl et al., 2018).

The interpolated anomaly profiles are constructed separately for both the drifter data and the SSP data. For the drifters, we combine the 5-cm data from the SURPACTs with the temperature data at $18 \mathrm{~cm}$ and $36 \mathrm{~cm}$ from the SC40 drifter. We assume a linear relationship between $\mathrm{T}$ and $\mathrm{S}$ and extrapolate temperature to estimate a salinity profile (starting from the observed surface salinity value) every 5 minutes. There is no well-defined model of the 
vertical salinity profile within a fresh layer; however, comparisons with the SSP data at 5, 12, and $23 \mathrm{~cm}$ suggest that the error caused by interpolating linearly between $5 \mathrm{~cm}$ and $18 \mathrm{~cm}$ on the drifters is likely small. The interpolation between the 23 and $54 \mathrm{~cm}$ depth SSP measurements, and below $36 \mathrm{~cm}$ on the drifters, is much less certain, so we assume a $20 \%$ uncertainty in the vertically integrated temperature and salinity anomaly.

A ratio, referred to as a penetration depth proxy, is defined as the depth-integrated salinity or temperature anomaly normalized by the surface anomaly. It is a proxy for the depth of the fresh surface layer: larger ratios indicate that the rainwater penetrated deeper into the water column. However, due to the relatively coarse vertical sampling and lack of deeper measurements, more refined estimates of the exact thickness and depth of the fresh layer are not possible. We first comment on the penetration scale proxy before presenting the freshwater anomalies and commenting on the heat content anomalies.

As the penetration scale proxies derived from the temperature and salinity data are very similar, we will only comment on the salinity penetration scale proxy. First, we notice, in a similar way as for surface records, more variability in the penetration scale proxy with the SSP than with the surface SURPACT records (Fig. 6a). On the other hand, we find rather similar-looking penetration scale proxies for the two SURPACT records, despite very different surface variations. For the drifters and for the SSP, there is an initial gradual increase of the penetration depth proxy during the rain, indicating that the fresh layer thickens with time. This trend is consistent with the initial time at which freshening and cooling starts at different levels. For example, the drifters show freshening/cooling at $5 \mathrm{~cm}$ at 13:50 GMT as soon as the rain starts (Fig. 6), then at $18 \mathrm{~cm}$ around 13:55 GMT, and after 14:00 GMT at 36 $\mathrm{cm}$ (not shown). Similarly, the SSP shows freshening at $5 \mathrm{~cm}$ that is well correlated with an increase in penetration scale proxy.

The immediate response to rain at the top level on the SSP and SURPACT is consistent with rain drops penetrating at least to $5 \mathrm{~cm}$. The lack of immediate response at $12 \mathrm{~cm}$ (SSP) or 18 $\mathrm{cm}$ (drifter) (not shown) indicates that water from the rain drops does not immediately penetrate to $12 \mathrm{~cm}$. The progressive vertical penetration of the freshening/cold signal from the rain is thus probably a result of vertical mixing induced by the heavy rain rate and the associated input in the ocean of momentum in vertical and horizontal direction, the latter of which contributes to vertical shear of the horizontal ocean current. For the SURPACTs, the 
increase in penetration depth proxy lasts until 14:15 GMT (after event B on SURPACT-N; Figure 3), when it exceeds $30 \mathrm{~cm}$ (a little larger for SURPACT-S than for SURPACT-N).

There is then little change in the proxy until the rain stops, followed by a gradual decrease of the penetration scale proxy to $<20 \mathrm{~cm}$ at 15:10 GMT (larger decrease for SURPACT-S than for SURPACT-N). The similarity of the decrease in penetration depth proxy between 14:30 and 15:10 GMT for the two SURPACTS, and the progressive disappearance of the freshening signal at $36 \mathrm{~cm}$ during that period (not shown), is suggestive either of relative advection of the initial fresh pool past the drifters or of horizontal divergence in the fresh pool layer causing a vertical thinning of the fresh and cool layer. Notice, however, that the penetration depth proxy estimated by the SSP also thins after 14:30 GMT, when the SSP crosses fluctuation 1, and remains relatively small $(\sim 15 \mathrm{~cm})$ until the wind speed intensifies at 14:50 GMT. On SSP, the penetration depth proxy for the period of the fluctuations (14:30 to 14:45 GMT) (top panel of Fig. 6) does not show much variability at the smaller 1-minute scale of the near-surface oscillations in T and S between 14:33 and 14:39 GMT. However, insufficient vertical resolution and uncertainties preclude interpreting the relationship between penetration depth proxy variability and variability in $\mathrm{T}$ or $\mathrm{S}$.

After 15:15 GMT, the wind intensifies and penetration depth increases to $>40 \mathrm{~cm}$, likely due to wind-induced vertical mixing.

The freshwater content, as expected, shows an initial increase during the rain event, followed by a decrease starting at 14:15 GMT, with a stronger signal observed at drifter-N (Fig. 6b). For drifter-S, there is much less decrease in freshwater content following the initial increase, despite large changes in penetration depth proxy and surface salinity (Fig. 6a). Maximum values of freshwater content exceed $4 \mathrm{~cm}$ for the two SURPACTs and the SSP. For the SSP, freshwater content exceeds $4 \mathrm{~cm}$ only briefly, during the crossing of filament 1 . Maxima in freshwater content are observed on drifter-N and drifter-S at the end of the heavy rain, with values of 8.3 and $4.5 \mathrm{~cm}$, respectively. These maxima do not coincide with the lowest salinity, which happens $~ 5-10$ minutes earlier (Fig. 6a).

It is interesting to compare these freshwater content estimates with gridded radar rain rates estimated every five minutes and the rain rates we calculated along the SURPACT trajectories (Fig. 6c). For both drifters, this radar estimate of total rain accumulation is on the order of 5 $\mathrm{cm}$. This has a similar magnitude to the observed total freshwater input estimated from the drifters (evaporation effects can be neglected on these times scales). In comparison, the rain 
4834. Discussion

measured on the ship only integrates to $1.3 \mathrm{~cm}$. Though flow distortion could be an issue, this value is significantly lower than the $5 \mathrm{~cm}$ observed very nearby by the ship's radar. The 1.3 $\mathrm{cm}$ rain accumulation value measured by the ship gauge is close to the lower bound of the freshwater content observed with salinity by the SSP $(\sim 2 \mathrm{~cm})$, but less than the peak values of freshwater content observed with salinity by the SSP (Figure 6b).

We will now comment on the near-surface heat content changes measured by the drifters and the SSP (Fig. 7). We first estimate the contribution to the heat content changes of the "no-rain surface heat flux', which is the net surface heat flux but without the contribution of cooling caused by the input in the surface layer of the colder rain drops. We assume that the average flux experienced by the drifters is the one estimated at the ship. Until 14:30 GMT, the "norain surface heat flux' contributes little to the upper ocean heat content change (which reaches $-0.2^{\circ} \mathrm{C} . \mathrm{m}$ ), and most of the observed heat content drop measured with the SURPACTs (or the SSP) is not explained by them. The most likely candidate for the difference between heat content change and the 'no-rain surface heat flux' is the contribution of the cooling effect of rain drops mixing into the upper ocean. We use the estimated change in freshwater content to estimate the raindrop temperature that would explain the part of the heat content change not explained by the 'no-rain surface heat flux'. This yields a raindrop temperature on the order of $24^{\circ} \mathrm{C}$ (Fig. 7): given the $10-\mathrm{m}$ air temperature on the order of $25^{\circ} \mathrm{C}$ at $95 \%$ saturation observed from R/V Revelle during the rain, this value of raindrop temperature is low but in the possible range (Gosnell et al., 1995).

The change in heat content observed after the end of the rain has to be related to either heat fluxes or relative advection. As the heat content coherently co-varies with freshwater content, and based on the small heat fluxes estimated from R/V Revelle and the relatively small changes in the T-S diagram (Fig. 4), it is likely that a large contribution to the observed changes in heat content after the rain originates from relative advection of the surface water with respect to the drifting platforms during that period. At 15:10 GMT, when the wind increases, vertical mixing with the warmer deeper water becomes a dominant contribution to the increase in heat content near the surface.

484 The radar data suggest that $\sim 5 \mathrm{~cm}$ of rain fell near the center of the surveyed area over about $90 \mathrm{~min}$ in a location where the SURPACTs drifted (Fig. 8). This series of events is also 
shown by observed temperature and salinity records (Fig. 6). Surprisingly, in situ sensors located on the R/V Revelle only measured $1.3 \mathrm{~cm}$ of rain accumulation despite being less than $2 \mathrm{~km}$ away from the drifters during the rain event (Fig. 6c). There are also very large differences in $\mathrm{T}$ and $\mathrm{S}$ between the two drifters, which were roughly $400 \mathrm{~m}$ apart, both during the last 30 minutes of rainfall (after event A) and during the 40 minutes afterwards (Fig. 3). SSP data from the R/V Revelle also show large spatial variability, suggesting filaments and inhomogeneities on scales of a hundred to a few hundred meters during the period with low wind that follows the rain events. Thus, we have two sets of questions to address:

4941. How does rain and/or wind heterogeneity at those short time and space scales contribute to 495 the spatial heterogeneity in the ocean?

4962. What is the contribution of oceanic processes involved in the spreading or mixing of the 497 surface freshwater pool?

We will first discuss (1). Because of the lack of data concerning spatial heterogeneity of the wind over the study area, it is difficult to assess this aspect. However, we hypothesize that wind variability likely happens at the scales involved with the heterogeneity of rain events, both in time and space. We thus only assess the impact of rain variability on ocean salinity. To examine this, we consider the SEA-POL radar rain data during the approximately 90 minutes when rain cells were in the study area (the higher-resolution X-band rain retrievals were not available during this survey). The SEA-POL rain rate product is calculated on a 1$\mathrm{km}$ grid, and shows intense isolated rain events happening on just one grid box (including a grid box located over the drifters). In addition, the radar samples for two minutes every five minutes, introducing uncertainties in local integrated rain amounts due to the intermittency of rainfall that is witnessed in the rainfall estimates from the sound records of the two SURPACTs. There is thus likely significant sub-grid variability in the rain field not captured by the SEA-POL dataset, even though radar-to-rain gauge comparisons show that the radar estimates are still very accurate over relatively short (minutes to hours) time scales and small spatial scales of a kilometer. For instance, when rain accumulation is integrated over the whole duration of the rain events, rain accumulation from SEA-POL data showed a similar magnitude as that estimated from the salinity records of the drifters $(5 \mathrm{~cm}$; Fig. 6); thus some of these resolution/sampling caveats might compensate when cumulated over time. 
517 The integrated effect of the rain heterogeneity is illustrated by integrating rainfall on

518 simulated particle trajectories (all having the horizontal velocity of the deployed drifters).

5191000 simulated particles were released at 13:40 GMT in a 10-km x 10-km square box

520

521

522

523

524

525

526

527

528

529

530

531

532

533

534

535

536

537

538

539

540

541

542

543

544

545

546

547

548 centered on the circle sampled by R/V Revelle. This is used in order to develop a statistical characterization, but does not take into account the likely spreading of particle trajectories.

Because the ship superstructure prevents SEA-POL from measuring rain aft of the ship, some regions with rain over the particles are not seen by the radar part of the time. Thus, the overall statistics are skewed towards lower accumulated rain (Fig. 8). On the other hand, when selecting areas which were covered at least $75 \%$ of the time by the radar, we get an almost Gaussian distribution of rain accumulation centered near $2.5 \mathrm{~cm}$, and no rain amount larger than $6 \mathrm{~cm}$.

The time distribution is rather similar whether we use all simulated particles or only the ones with $75 \%$ time coverage, and peaks near 14:00 GMT, a little earlier than what was observed with the two real drifters and the R/V Revelle. This slightly earlier peak in rain observed with the radar is because regions towards the southern/ southeastern part of the domain experienced rainfall earlier than at the ship's location (Fig. 8). The distribution of rainfall suggests that it rained in a large part of the domain, even though individual rain cells were very small (a few kilometers across). Within the region measured by the radar more than $75 \%$ of the time, there is a clear structure, with heavier rainfall near the 'real' drifters and in the southeast quadrant of the circle, with 1-3 km wide patches of heavy rainfall amounts. The plot with all simulated drifters suggests that there was at least another area with large total rainfall amount in the southwest, but we cannot assess the accuracy of these rain rates because of insufficient temporal sampling in the radar dataset.

(2) We will now discuss the contribution of oceanic processes to the fresh pools spreading and mixing. The large changes in $\mathrm{T}$ and $\mathrm{S}$ observed by the drifters (in particular drifter $\mathrm{S}$ ) after the end of the rain between 14:30 and 15:20 GMT are likely not induced solely by vertical mixing from wind input, as indicated by the shallowing of the penetration depth of the temperature and salinity anomalies (Fig. 6a). This lack of vertical mixing is also supported by the lack of cooling/freshening at the deepest levels of the SSP before the wind picks up at 14:50 GMT along the R/V Revelle track.

Thus, the large $\mathrm{T}$ and $\mathrm{S}$ changes seen by the drifters until the wind picks up are likely associated with horizontal advection of surface waters relative to the drifters. As noted earlier, 
the drogue depth and the drifting characteristics of the drifters are probably more characteristic of the drift below $25 \mathrm{~cm}$ depth than above, and thus do not properly track the flow in the top freshest layer, which is confined to the upper $25 \mathrm{~cm}$.

There are multiple factors which would explain why the seawater velocity would be different in this top layer. First, raindrops deposit horizontal momentum in this layer. During the rain event, the horizontal wind and thus the drops' horizontal momentum could easily be on the order of $1 \mathrm{~m} / \mathrm{s}$ or more. For $5 \mathrm{~cm}$ of total rainfall, drops having this momentum deposited into a $25-\mathrm{cm}$ penetration depth would generate a $20 \mathrm{~cm} / \mathrm{s}$ current in the upper $25 \mathrm{~cm}$. In an hour, this would induce more than $700 \mathrm{~m}$ of displacement of the freshwater lens relative to the drifters, which might be around half the scale of the rain cells. In addition, the spatial heterogeneity of rainfall (Fig. 8) can induce large horizontal gradients in surface density, and thus in pressure with its associated horizontal acceleration $[-1 / \rho \operatorname{grad}(\mathrm{P})]$ after the fast, but very small barotropic dynamic adjustment. Assuming a 3-cm gradient of rain accumulation over a 1-km horizontal scale, as seems possible from Figure 8 is associated with an acceleration of $10^{-5} \mathrm{~m} \mathrm{~s}^{-2}$. Horizontal surface convergence/divergence induced by the spatial heterogeneity in the momentum input of rain and wind in the stratified surface layer will also generate horizontal pressure gradients.

In linear theory, the surface-trapped pressure gradients will generate surface-trapped gravity waves in this highly stratified surface layer at periods set by the spatial and temporal scales of the forcing, as well as their dispersion relation (internal gravity wave period cut off is at a period of 30-s or less). The 5-cm total rain amount at the drifter site produces a relative density anomaly of $7.0 \times 10^{-3} \mathrm{~kg} \mathrm{~m}^{-3}$ over $25 \mathrm{~cm}$, which corresponds to phase speeds on the order of $10-15 \mathrm{~cm} / \mathrm{s}$. Surface gravitational currents generated by the density gradients, as well as the sheared background currents and the currents associated with large amplitude internal waves have similar magnitude to this phase speed, thus non-linear effects are expected to be large (Soloviev et al., 2002, 2015), and fronts could form. Nonetheless, oscillations in surface currents at periods of a few minutes and longer are also likely to be associated with internal waves, both as the boundary of the fresh pool evolves and due to the observed intermittency of the rain and hence the momentum input. Initially, these oscillatory horizontal surface currents will be surface-trapped.

The oscillations in surface salinity over time that were observed for SURPACT-S during the half hour following the rain and preceding the period of minimum surface salinity (Fig. 3) 
6085. Conclusions

might result from relative horizontal advection by these internal wave currents in the presence of large horizontal gradients of surface salinity. Similar waves are also likely to have been crossed by the SSP towed by the R/V Revelle (14:33 to 14:39 GMT) (Fig. 4), which was spatially rather close to SURPACT-S (less than 1-km). As we do not know the directional propagation speed of the waves at SURPACT-S and cannot fully assess whether it is the same wave packet crossed by the SSP, as the distance to SURPACT-S could be a large multiple of the wave length, it is not possible to directly assess the directional wave propagation speed, and how they affect the fluctuations that were seen on the SSP records. The structures are not stationary during the SSP survey, which could result in distortion of the wave pattern, but by less than $10 \%$ with the expected internal wave speeds of $10-15 \mathrm{~cm} / \mathrm{s}$. Interestingly, on SSP, the oscillations are witnessed after crossing the pool with lowest salinity (event 1) in the south-east part of the survey, whereas on SURPACT-S they are seen as S decreases, maybe on the eastern front of the freshest water which was initially probably to its north based on SURPACT-N record. On the other hand, the very fresh water of SSP event (1) is to the southeast of SURPACT-S. This suggests either multiple fresh pools, or the possibility that the fresh water pool fronts might have started to be associated with filaments, which are crossed in different instances by the SSP (events (1) to (4), for example).

Currents associated with the gravity waves, the displacements of the fresh water pool fronts and its filaments will result in spreading the fresh/cool pool: typically by $\sim 400 \mathrm{~m}$ over an hour, based on the density anomaly and linear wave theory. Such spreading is associated with a shallowing of the pool: for an initial fresh pool $1-\mathrm{km}$ wide, the shallowing is by a factor of two in 1 hour. This is not far to what we observe on the two drifters, before wind-induced mixing sets in (Fig. 6a). Obviously, however, because of the heterogeneity of rainfall conditions in this surveyed area, we would need much more in situ estimates to be able to quantify precisely the spreading rate. Also, it is possible that some mixing happens near the density fronts, in particular if the weak winds opposed its propagation resulting in density overturns (Soloviev et al., 2002).

The area surveyed on November 9 during the 2017 SPURS- 2 cruise on R/V Revelle in the equatorial Pacific was less than $10 \mathrm{~km}^{2}$. This survey, which was characterized by intense rain events over 90 minutes, experienced huge spatial and temporal variability in its surface temperature and salinity during the rainfall periods and also for more than 30 minutes 
afterwards. During that period, spatial heterogeneity in salinity appeared to reach more than 5 psu, although the sampling in only three places makes it difficult to quantify the magnitude and spatial scales of the variability. Even at locations separated by only $400 \mathrm{~m}$, surface salinity presented very different time evolution, with differences between sampling points often exceeding 4 psu, even more than 30 min following the rainfall. The weak wind conditions and highly heterogeneous and intermittent rain events witnessed are key elements in generating this strong surface salinity variability. Interestingly, point-measuring precipitation gauges mounted on the R/V Revelle measured only a total of $1.3 \mathrm{~cm}$ of rain, but the integrated freshwater measured by the SSP suggested that the survey crossed areas which had experienced more than $3 \mathrm{~cm}$ of rain. Similarly, the integrated freshwater measured with the drifters suggested that more than $5 \mathrm{~cm}$ of rain fell, a large variability over a scale of a few kms. A particularly unusual characteristic of this event is that the fresh pool thinned vertically after the end of the rain, which may have been related to its horizontal spreading, a result of ocean dynamics. The thinning suggests a very small contribution of vertical diffusion (which tends to thicken rain layers), consistent with the weak winds We also suggest that horizontal advection of the surface fresh pools relative to slightly deeper waters, and ocean dynamics (internal waves, fronts, filaments) associated with the fresh pools have largely modified the spatial distribution of fresh water and contributed to the evolution of surface salinity in the hour following the rain when wind was still weak.

This survey did not resolve all the relevant spatial scales of the strong variability. For rainfall, this is the case both in time (rainfall intermittency happens at timescales of hundreds of seconds) and in space (rainfall appears to vary on scales smaller than $1 \mathrm{~km}$ ). The SEA-POL radar data provide broad spatial coverage, but the rain rate estimates are averaged over 2 minutes every 5 minutes so it is not possible to observe the intermittency at timescales shorter than a few minutes. We also cannot fully separate surface $\mathrm{T}$ and $\mathrm{S}$ variability that is locally 638 forced by variability in rainfall from that which is due to ocean dynamics. For example, the 639 large difference in maximum freshwater content and minimum surface salinity between drifters SURPACT-N and SURPACT-S (Fig. 6b) may be related to differences in rainfall, to subtle differences in the momentum input from the rain and wind, or to the inhomogeneity of the spreading of the fresh pools. The latter effects could have induced a local convergence at SURPACT-N of the freshwater, which probably would also reduce the vertical mixing. The surveys also suggest that internal gravity waves or other ocean dynamics with periods on the 
order of 5 minutes or less may induce large T/S surface variability, as well as fronts and filaments associated with the rain-induced fresh pools. This is a topic for further research.

This strong variability limits our ability to accurately determine the relation between local observations of $\mathrm{T}$ and $\mathrm{S}$ near the surface and local wind and rain conditions in such extreme events, whether they are sampled by drifters, sea snakes, or other surface devices (such as the probes at the bow of the ships used during COARE) (Boutin et al., 2016). Strong rain events such as observed here generating anomalies having almost $10 \mathrm{psu}$ and $1.5^{\circ} \mathrm{C}$ maximum amplitudes, can be trapped so close to the surface that they would be missed by measurements made at depths of $1 \mathrm{~m}$ (and greater). This is significant when interpreting S/T data from platforms such as Argo floats, ship-mounted thermosalinographs, or even the salinity drifters that measure at $40-50 \mathrm{~cm}$ depth (Reverdin et al., 2012 ; Centurioni et al., 2015; Dong et al., 2017; Volkov et al., 2019). On the other hand, the rain-generated cooling would be sensed by the hull temperature sensor at $18 \mathrm{~cm}$ depth on SVP drifters.

How common are decreases in SST and SSS close to $1.5^{\circ} \mathrm{C}$ and 10 psu such as we found? We are anecdotally aware of two other documented (though not published) occurrences of very large SST and SSS decreases, one during the SPURS-2 cruise in 2016 and one from a drifter of the same type as used here (but drogued at $15 \mathrm{~m}$ ) in the tropical Atlantic ITCZ region. Such strong surface cooling and freshening requires very low winds during rain to minimize vertical mixing induced by the wind stress and momentum input by the drops (Asher et al., 2014). These conditions are uncommon, as intense tropical convection is often associated with downdrafts reaching the surface under or near the rain cells. However, the ITCZ is known to be a weak wind area due to horizontal convergence of the trade winds. What is special in the observations of this paper is the relatively long duration of the period of very weak winds, which lasted at the drifters over forty minutes after the end of the rain. These low-wind conditions are very common in the ITCZ, hence why they are referred to as the Doldrums.

Even if such low-wind rain events are not frequent (a tail in the distribution of rain events), they could have an impact in the overall oceanic freshwater budget: a missed surface freshwater component in budgets based on in situ measurements collected most of the time at $1 \mathrm{~m}$ or more (for example, Yu, 2011). In rainy regions, such as near the ITCZ, one could also expect that strong rain events with weak winds will modify the relationship derived from satellite data between rain rate and SSS changes at scales typically of $50 \mathrm{~km}$ or more (Supply 
677 et al., 2018, 2019). In such regions, it could also impact the overall satellite reconstruction of 678 SST, as SST is not measured in or near areas of intense rain. This particular event has also 679 been shown to strongly influence surface $\mathrm{pCO}_{2}$ and air-sea gas exchange (D. Ho, pers. Comm. 680 2018). From an atmospheric point of view, it would be interesting to better understand the 681 atmospheric dynamical context in which such rain cells develop, and whether there is some 682 local feedback from the cold pool formed by the rain deposition on the organization of the 683 rain cells. 
686 AS and GR acknowledge CNES support for this study through a TOSCA grant for SMOS

687 studies. AS is supported by a SU Ph. D. grant. KD, EJT, and WEA acknowledge support from 688 National Science Foundation grant OCE-1458759 and NASA grant NNX15AF68G. EJT was 689 also supported by NASA Ocean Salinity Science Team Grant 80NSSC18K1330. The 2017 690 SPURS-2 cruise was funded through these grants. The crew on board the R/V Revelle greatly 691 contributed to the success of the drifter and SSP deployments. Strong support for the SEA692 POL radar and data analysis was provided by S. A. Rutledge at Colorado State University. 693 The data are archived on NASA PO.DDAC as part of the SPURS-2 dataset, and will soon be 694 all accessible there. The SSP data are at http://dx.doi.org/10.5067/SPURS2-SSP00 and the 695 ship's meteorological data are at http://dx.doi.org/10.5067/SPURS2-MET00. Advice and 696 comments by Jacqueline Boutin were very useful. The support team at SMRU (Philip Lovell 697 and Simon Halliwell) strongly contributed to develop and to manufacture the SURPACT.

698

699 


\section{References}

702

703

704

705

706

707

708

709

710

711

712

713

714

715

716

717

718

719

720

721

722

723

724

725

726

727

728

729

Asher, W. E., A. T. Jessup, R. Branch, and D. Clark (2014). Observations of rain-induced near surface salinity anomalies, J. Geophys. Res. Oceans, 119, 5483-5500, doi:10.1002/2014JC009954.

Asher, W.E., K. Drushka, A.T. Jessup, E.J. Thompson, and D. Clark (2019). Estimating raingenerated turbulence at the ocean surface using the active controlled flux technique. Oceanography 32(2):108-115, https://doi.org/10.5670/oceanog.2019.218.

Bellenger, H., K. Drushka, W. Asher, G. Reverdin, M. Katsumata, W. Watanabe, and K. Ando (2017). Extension of the prognostic model of sea surface temperature to rain-induced cool and fresh lenses. J. Geophys. Res., 121, 2841-2855, doi:10.1002/2015JC011302.

Boutin, J., N. Martin, G. Reverdin, S. Morisset, X. Yin, L. Centurioni, and N. Reul (2014). Sea surface salinity under rain cells: SMOS satellite and in situ drifters observations, $J$. Geophys. Res. Oceans, 119, 5533-5545, doi:10.1002/2014JC010070.

Boutin, J., et al. (2016). Satellite and in situ salinity: Understanding near-surface stratification and sub-footprint variability, Bull. Am. Meteorol. Soc., 89, 1111-1125, doi:10.1175/2008BAMS2462.1

Centurioni, LR, V. Hormann, Y. Chao, G. Reverdin, J. Font, and D. K. Lee (2015). Sea surface salinity observations with Lagrangian Drifters in the Tropical North Atlantic During SPURS: Circulation, fluxes, and comparisons with remotely sensed salinity from Aquarius. Oceanography, 28, 96-105, 10.5670/oceanog.2015.08

Clayson C. A., J. B. Edson, A. Paget, R. Graham, and B. Greenwood (2019). The effects of rainfall on the atmosphere and ocean during SPURS-2, Oceanography, 32, 86-97, https://doi.org/10.5670/oceanog.2019.216.

Dong, S., D.L. Volkov, G. Goni, R. Lumpkin, and G. Foltz (2017). Near-surface salinity and temperature structure observed from dual-sensor drifters in the subtropical South Pacific. $J$. Geophys. Res. Oceans , 122, doi:10.1002/2017JC012894

Drucker, R., and S. C. Riser (2014). Validation of Aquarius sea surface salinity with Argo: Analysis of error due to depth of measurement and vertical salinity stratification. J. Geophys. Res., 119, https://doi.org/10.1002/2014JC010045. 
Drushka, K., W. E. Asher, A. T. Jessup, E. Thomson, S. Iyer, and D. Clark (2019). Capturing fresh lenses with the Surface Salinity Profiler. Oceanography , 32, 76-85, https://doi.org/10.5670/oceanog.2019.215

Drushka, K., W. E. Asher, B. Ward, and K. Walesby (2016). Understanding the formation and evolution of rain-formed fresh lenses at the ocean surface. J. Geophys. Res., 121, doi:10.1002/2015JC011527.

Gosnell, R. C. Fairall, and P. J. Webster (1995). The sensible heat of rainfall in the tropical ocean. J. Geophys. Res. 100, 18437-18442.

Ho, D. T., C. J. Zappa, W. R. McGillis, L. F. Bliven, B. Ward, J. W. H. Dacey, P. Schlosser, and M. B. Hendricks (2004). Influence of rain on air-sea gas exchange: Lessons from a model ocean. J. Geophys. Res., 109, C08S18, doi:10.1029/2003JC001806.

Hodges, B. A., and D. A. Fratantoni (2014). AUV observations of the diurnal surface layer in the North Atlantic salinity maximum. J. Phys. Ocean., 44, 1595-1604, doi:10.1175/JPO-D13-0140.1.

Hormann, V, L. R. Centurioni, and G. Reverdin (2015). Evaluation of drifter salinities in the subtropical North Atlantic. J. Atmosph. and Ocean. Tech., 32, 185-192. 10.1175/jtech-d-1400179.1

Huffman, G.J., E.F. Stocker, D.T. Bolvin, E.J. Nelkin, Jackson Tan (2019), GPM IMERG Early Precipitation L3 Half Hourly 0.1 degree x 0.1 degree V06, Greenbelt, MD, Goddard Earth Sciences Data and Information Services Center (GES DISC), Accessed: [2019/10/29], 10.5067/GPM/IMERG/3B-HH-E/06

Lindstrom, E.J., J.B. Edson, J.J. Schanze, and A.Y. Shcherbina (2019). SPURS-2: Salinity Processes in the Upper-ocean Regional Study 2. The eastern equatorial Pacific experiment. Oceanography 32(2):15-19, https://doi.org/10.5670/oceanog.2019.207.

Novelli, G., C.M. Guigand, C. Cousin, E.H. Ryan et al. (2017). A biodegradable surface drifter for ocean sampling on a massive scale. J. Atmos. Oceanic Technol., 34, 2509-2532, https://doi.org/10.1175/JTECH-D-17-0055.1.

Nystuen, J.A., and E. Amitai (2003). High temporal resolution of extreme rainfall rate variability and the acoustic classification of rainfall. J. Geophys. Res., 108, D8, 8378, doi:10.1029/2001JD001481 
760

761

762

763

764

765

766

767

768

769

770

771

772

773

774

775

776

777

778

779

780

781

782

783

784

785

786

787

Price, J.F. (1979). Observations of a Rain-Formed Mixed Layer. J. Phys. Oceanogr., 9, 643649, https://doi.org/10.1175/1520-0485(1979)009<0643:OOARFM>2.0.CO;2

Reverdin, G. Reverdin, G., S. Morisset, J. Boutin, and N. Martin (2012). Rain-induced variability of near sea-surface T and S from drifter data, J. Geophys. Res., 117, C02032, doi:10.1029/2011JC007549.

Reverdin, G., S. Morisset, D. Bourras, N. Martin, A. Lourenço, J. Boutin, C. Caudoux, J. Font, and J. Salvador (2013). A SMOS surface drifter for air-sea interaction (SURPACT). Oceanography, 26, 48-57.

Roquet, F., J.-B. Charrassin, S. Marchand, L. Boehme, M. Fedak, G. Reverdin, and C. Guinet (2011). Delayed-mode calibration of hydrographic data obtained from animal-borne satellite relay data loggers. Journal of Atmospheric and Oceanic Technology, 28(6), 787-801.

Rutledge, S. A., V. Chandrasekar, B. Fuchs, J. George, F. Junyent, P. Kennedy and B. Dolan (2019a). Deployment of the SEA-POL C-band polarimetric radar to SPURS-2.

Oceanography, 32, 50-57, https://doi.org/10.5670/oceanog.2019.212.

Rutledge, S.A., V. Chandrasekar, B. Fuchs, J. George, F. Junyent, B. Dolan, P.C. Kennedy, and K. Drushka (2019b): SEA-POL GOES TO SEA. Bull. Amer. Meteor. Soc., in press, https://doi.org/10.1175/BAMS-D-18-0233.1

Shcherbina, A.Y., E. d'Asaro, and R.R. Harcourt (2019). Rain and sun create slippery layers in the eastern Pacific fresh pool. Oceanography, 32, 2, 98-107.

Soloviev, A., and R. Lukas (1996). Sharp frontal interfaces in the near-surface layer of the ocean in the western equatorial Pacific warm pool. J. Phys. Oceanogr., 27, 999-1017.

Soloviev, A., and R. Lukas (2006). The Near-Surface Layer of the Ocean: Structure, Dynamics and Applications, Atmospheric and Oceanographic Sciences Library, vol. 31, 574 pp., Springer, Dordrecht, Netherlands, doi:10.1007/1-4020-4053-9.

Soloviev, A., R. Lukas, and H. Matsuura (2002). Sharp frontal interfaces in the near-surface layer of the tropical ocean, J. Mar. Syst., 37(1), 47-68.

Soloviev, A. V., S. Matt, and A. Fujimura (2015). Three-dimensional dynamics of freshwater lenses in the ocean's near-surface layer, Oceanography, 28, 142-149. 
SPURS-2 Planning Group (2015). From salty to fresh-Salinity Processes in the Upper-ocean Regional Study-2 (SPURS-2): Diagnosing the physics of a rainfall-dominated salinity minimum. Oceanography 28, 150-159, https://doi.org/10.5670/oceanog.2015.15.

Supply, A., J. Boutin, G. Reverdin, J.-L. Vergely, and H. Bellenger (2019). Variability of satellite sea surface salinity under rainfall. In: Satellite Precipitation Measurement, V. Levizzani, C. Kidd, D. B. Kirschbaum, C. D. Kummerow, K, Nakamura, and F. J. Turk (Eds.), Springer Nature, Dordrecht, due March 24, 2020. SBN 978-3-030-24567-2

Supply, A., J. Boutin, J. L. Vergely et al. (2018). Precipitation Estimates from SMOS SeaSurface Salinity. Q J R Meteorol Soc; 144 ( Suppl. 1): 103- 119.

https://doi.org/10.1002/qj.3110.

ten Doeschate, A., G. Sutherland, H. Bellenger, S. Landwehr, L. Esters, and B.Ward (2019). Upper ocean response to rain observed from a vertical profiler. Journal of Geophysical Research: Oceans, 2018JC014060, https://doi.org/2018JC014060.

Thompson, E. J., J. N. Moum, C. W. Fairall, and S. A. Rutledge ( 2019). Wind limits on rain layers and diurnal warm layers. Journal of Geophysical Research: Oceans, 124, 897-924. https://doi.org/10.1029/2018JC014130

Volkov D.L., S. Dong, G. Foltz, G. Goni, and R. Lumpkin (2019). Observations of nearsurface salinity and temperature structure with dual-sensor Lagrangian drifters during SPURS-2, Oceanography, 32(2):66-75, https://doi.org/10.5670/oceanog.2019.214.

Wurl, O., W. M. Landing, N. I. H. Mustaffa, M. Ribas-Ribas, C. R. Witte, C. J. Zappa (2018). The Ocean's skin layer in the tropics. J. Geophys. Res. C, 24, doi:10.1029/2018JC014021. Wijesekera, H. W., C. A. Paulson, and A. Huyer (1999). The effect of rainfall on the surface layer during a westerly wind burst in the western equatorial Pacific. J. Geophys. Res., 29, 612-632.

Yu, L. (2010), On Sea Surface Salinity Skin Effect Induced by Evaporation and Implications for Remote Sensing of Ocean Salinity, J. Phys. Oceanogr., 40(1), 85-102, doi:10.1175/2009JPO4168.1.

Yu, L. (2011). A global relationship between the ocean water cycle and near-surface salinity. J. Geophys. Res., 116, doi:10.1029/2010JC006937.

Zappa, C.J., D.T. Ho, W.R. McGillis, M.L. Banner, J.W. Dacey, L.F. Bliven, B. Ma, and J. Nystuen (2009). Rain-induced turbulence and air-sea gas transfer. J. Geophys. Res. 114(C7), https://doi.org/10.1029/2008JC005008. 
821 Figure 1: Track of R/V Revelle (red) and of the towed SSP (color-coded with measured SSS)

822 during the survey on November 9 as well as the tracks of the two drifters (also color-coded

823 for SSS from their deployment at 13:30 until 15:30 GMT; drifters moving towards the

824 east/south-east). Key events are mentioned on the R/V Revelle track. Step 1 corresponds to

825 the first big rain events in the center of the domain; step 2 with the time of maximum rainfall;

826 step 3 is close to the end of rainfall and when the SSP crossed a freshwater pool; step 4

827 corresponds to the time drifter (S) was in a fresh pool, whereas the wind started to increase on

828 R/V Revelle. The vectors correspond to wind vectors at the different steps. (AS: ADD steps

829 on figure)

830 Figure 2: Photographs showing the SURPACT drifters (upper left) and the other drifters to

831 which they are attached (upper right) just before deployment, as well as SURPACT and SSP ready

832 to be deployed with their key instruments (lower right and left panels respectively)

833 Figure 3: Time series of upper level (at $5 \mathrm{~cm}$ for SSP and for the drifters) T (green) and S(red)

834 as well as rainfall (blue) and wind speed (black) for SSP and R/V Revelle (3a) and for drifters

$835(\mathrm{~N})$ and $(\mathrm{S})(3 \mathrm{~b}, 3 \mathrm{c})$. For the drifters, "rain rate" is an unscaled indicator based on the

836 microphone measurements; the black curves represent the power spectral energy of vertical

837 acceleration of the SURPACT at 0.75-s period (scales not indicated), which is taken as a

838 proxy for local wind speed. SSP T and S data are 15-s median-filtered records, whereas wind

839 and rainfall rate from R/V Revelle are 1-minute averages. For the drifters, data are 21-s

840 averages; the vertical acceleration spectral energy are further smoothed with a 1-minute

841 running mean. On 3a, the cool/fresh events 1, 2, 3, 4 are indicated, and on 3b, cool fresh

842 events A, B, C are indicated.

844 Figure 4: SST-SSS scatter diagram from the two drifters with overlaid density contours

845 (sigma units). The data points are color-coded as a function of time since the beginning of

846 rain (in hours), when SSS-SST was close to the north-east corner of the plot. Rain stops at 0.8 847 hrs.

848 Figure 5: SSP data between 14:30 and 14:54. (5a) is a zoomed version of Fig. 3a and thus 849 same legend caption. (5b) and (5s) present the SSP 15-s median-filtered S and T data at the 850 different levels from 5-cm to 54-cm depth. The 5-cm level is from a pumped sea snake, 
whereas the other levels are from instruments placed on the SSP keel. Numbers 1 to 4 refer to particular fresh/cool filaments crossed by the SSP.

Figure 6: (a) Time series of penetration depth (full line) and $5 \mathrm{~cm}$ salinity (dashed lines) from 15-s median data from the SSP (black) and from the 5-minute sampled drifter time series (blue and red lines, respectively, for drifter $\mathrm{N}$ and $\mathrm{S}$ ). The vertical scale of penetration depth is only up to $50 \mathrm{~cm}$, to limit interpolation/extrapolation errors. (b) Vertically integrated freshwater contents reported as equivalent rainfall amounts in cm for SSP (black) and drifters $\mathrm{N}$ (blue) and S (red; indicative 20\% error bars are also plotted). (c) Integrated rainfall amount from R/V Revelle and from the SEA-POL 1-km resolution radar data interpolated to the drifter locations.

Figure 7: Vertically integrated temperature anomaly budget at SURPACT-S. The heat content loss term is the measured integrated temperature anomaly, whereas no-rain heat flux (blue) is based on the average net no-rain heat loss measured during the period by R/V Revelle, and rain cooling (red) is estimated from the collocated radar rain rates, assuming a rain drop temperature of $24^{\circ} \mathrm{C}$ (which optimizes the change observed until 14:20).

Figure 8: Statistics of rainfall at 1000 virtual drifters in a 10-km x 10-km square box. The virtual drifters have the same trajectory as drifter $\mathrm{N}$, and rainfall is from SEA-POL radar rain rate estimations between 13:30 and 14:45 UTC : Top, left) accumulated rainfall at the drifter averaged positions; black line indicates the track of R/V Revelle during this time period;; magenta and red lines the trajectories of the two drifters; Top, right) accumulated rainfall only for the 368 virtual drifters for which the SEA-POL radar provides rain rate information more than $75 \%$ of the time; Bottom, left) Averaged time series of rain rate measured by virtual drifters (blue, all drifters; orange, drifters with more than $75 \%$ of time coverage by the radar); Bottom, right) histogram of accumulated rainfall among all the drifters (blue) and among the drifters with more than $75 \%$ of time coverage by the radar (orange). 


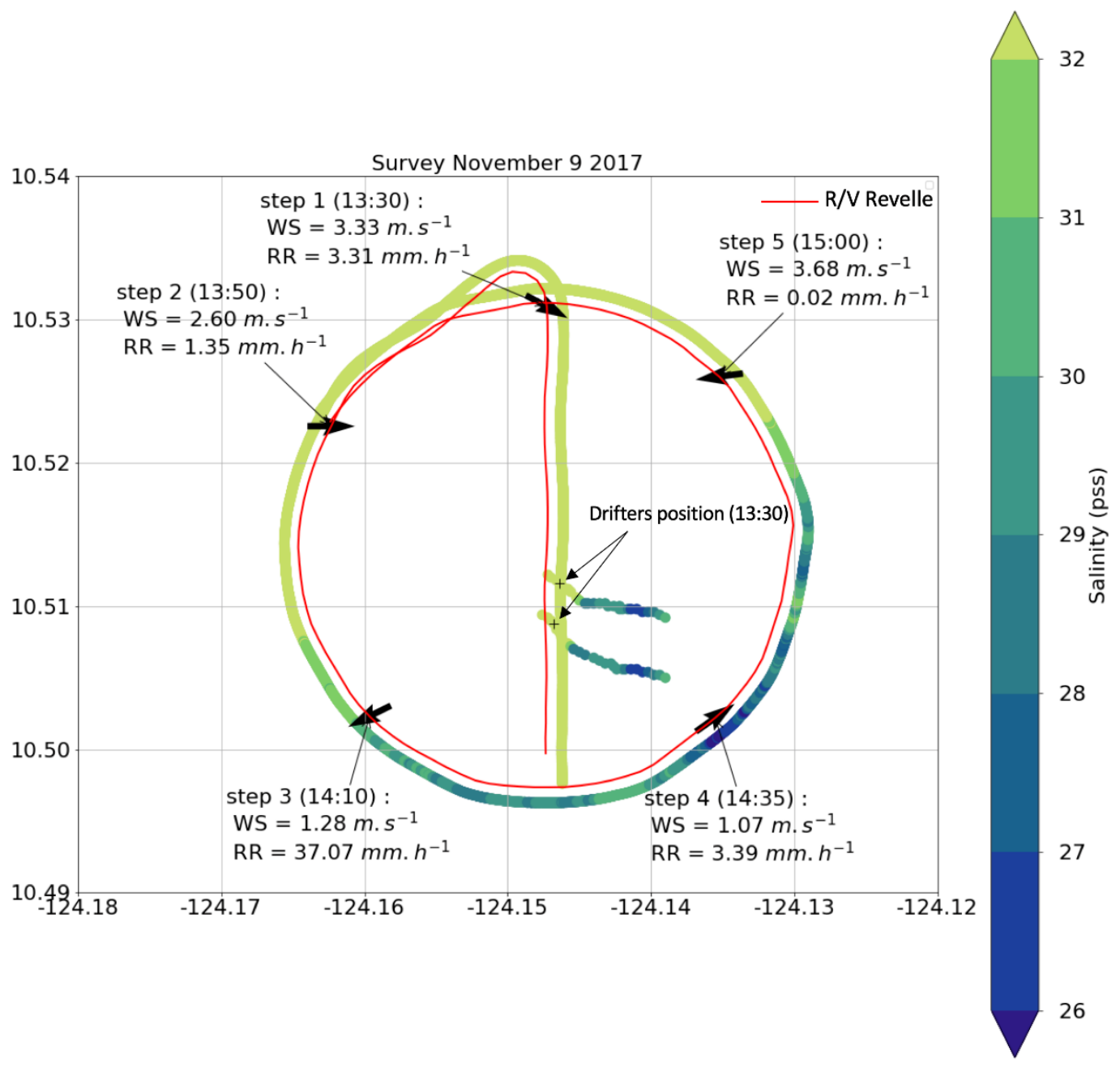

879

Figure 1: Track of R/V Revelle (red) and of the towed SSP (color-coded with measured SSS)

881 during the survey on November 9, 2017 as well as the tracks of the two drifters (also color-

882 coded for SSS from their deployment at 13:30 until 15:30 GMT; drifters moving towards the

883 east/south-east). Key events are labeled on the R/V Revelle track. Step 1 corresponds to the

884 first big rain events in the center of the domain; step 2 is the time of maximum rainfall; step 3

885 is close to the end of rainfall and when the SSP crossed a freshwater pool; step 4 corresponds

886 to the time drifter $\mathrm{S}$ was in a fresh pool, whereas the wind started to increase on R/V Revelle.

887 The arrows correspond to wind vectors at the different steps. 

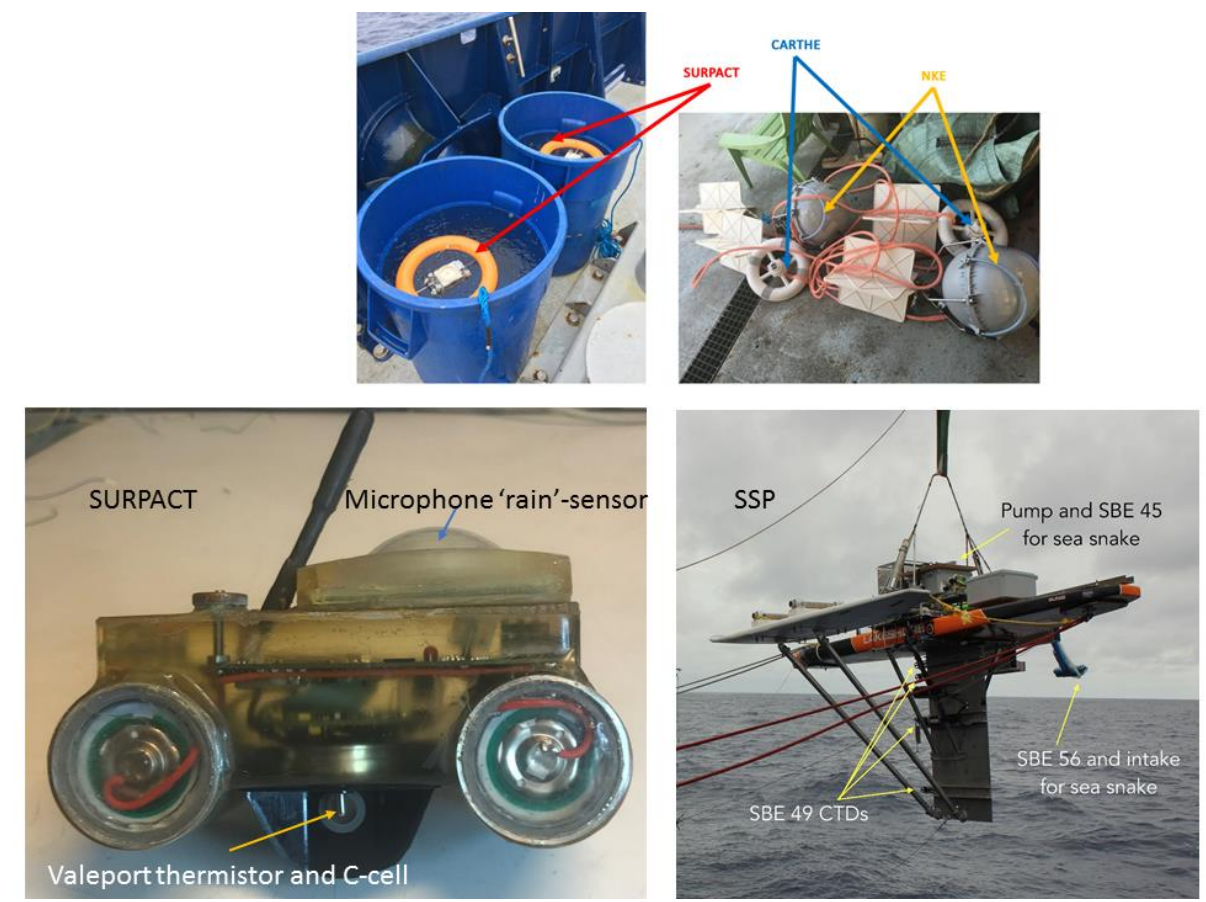

892 Figure 2: Photographs showing the SURPACT drifters (upper left) and the other drifters to which they 893 are attached (upper right) just before deployment, as well as SURPACT and SSP ready to be deployed 894 with their key instruments (lower right and left panels respectively)

895

896

897 


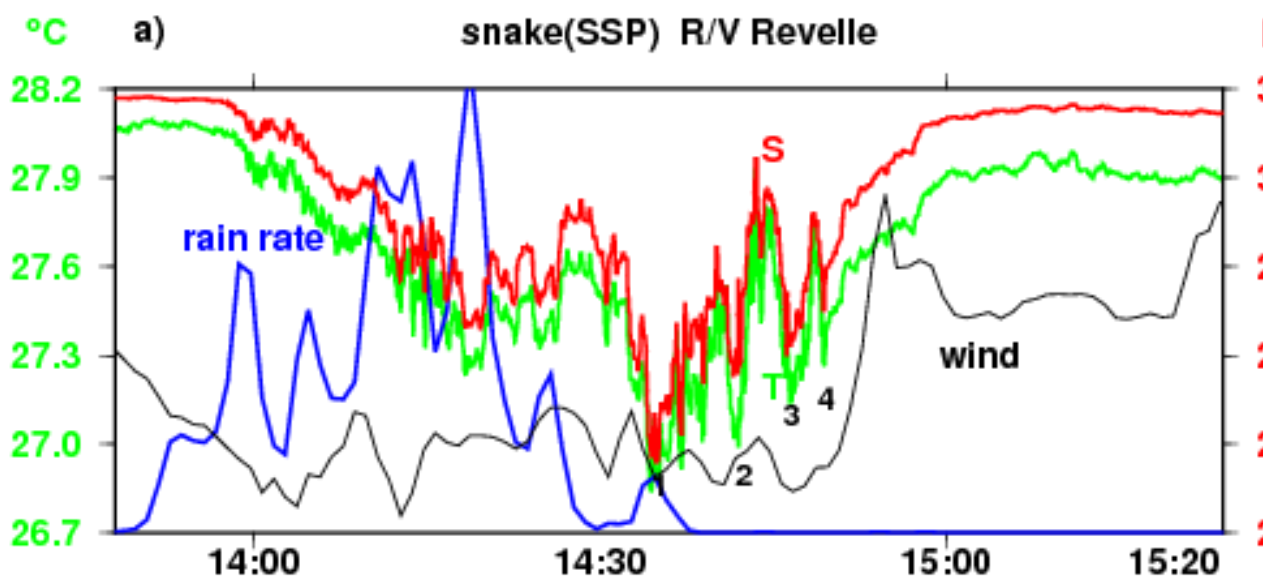

psu $\mathrm{cm} / \mathrm{h} \mathrm{m} / \mathrm{s}$

29.5

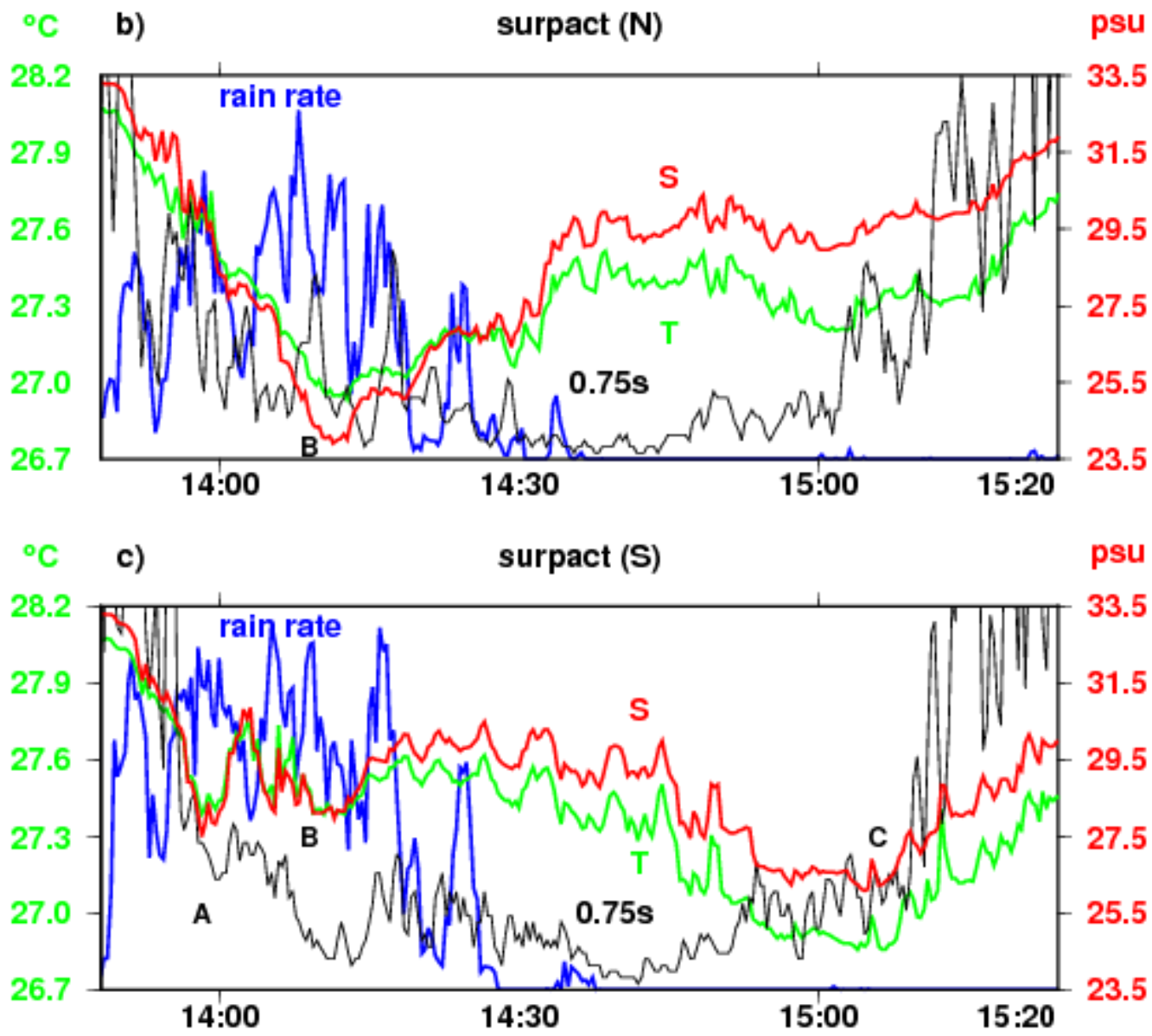

Figure 3: Time series of upper level (at $5 \mathrm{~cm}$ for SSP and for the drifters) T (green) and S(red) as well as rainfall (blue) and wind speed (black) for SSP and R/V Revelle (3a) and for drifters $(\mathrm{N})$ and $(\mathrm{S})(3 \mathrm{~b}, 3 \mathrm{c})$. For the drifters, "rain rate" is an unscaled indicator based on the microphone measurements; the black curves represent the power spectral energy of vertical acceleration of the SURPACT at 0.75 -s period (scales not indicated), which is taken as a proxy for local wind speed. SSP T and S data are 15-s median-filtered records, whereas wind and rainfall rate from $\mathrm{R} / \mathrm{V}$ Revelle are 1-minute averages. For the drifters, data are 21-s 
averages; the vertical acceleration spectral energy are further smoothed with a 1-minute running mean. On 3a, the cool/fresh events 1, 2, 3, 4 are indicated, and on 3b, cool.fresh events A, B, C are indicated.

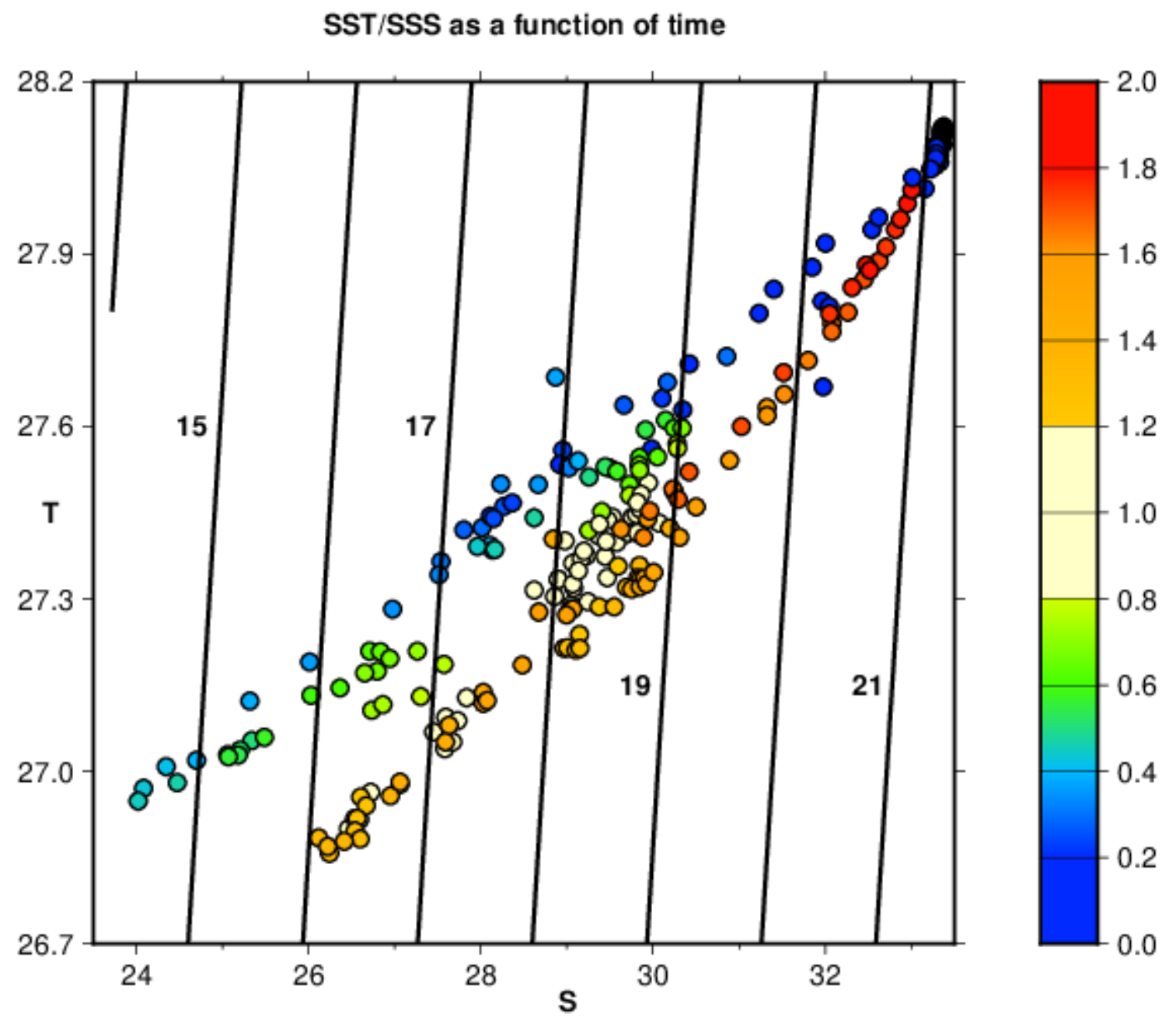

911

912 Figure 4: SST-SSS scatter diagram from the two drifters with overlaid density contours

913 (sigma units). The data points are color-coded as a function of time since the beginning of

914 rain (in hours), when SSS-SST was close to the north-east corner of the plot. Rain stops at 0.8 915 hours. 

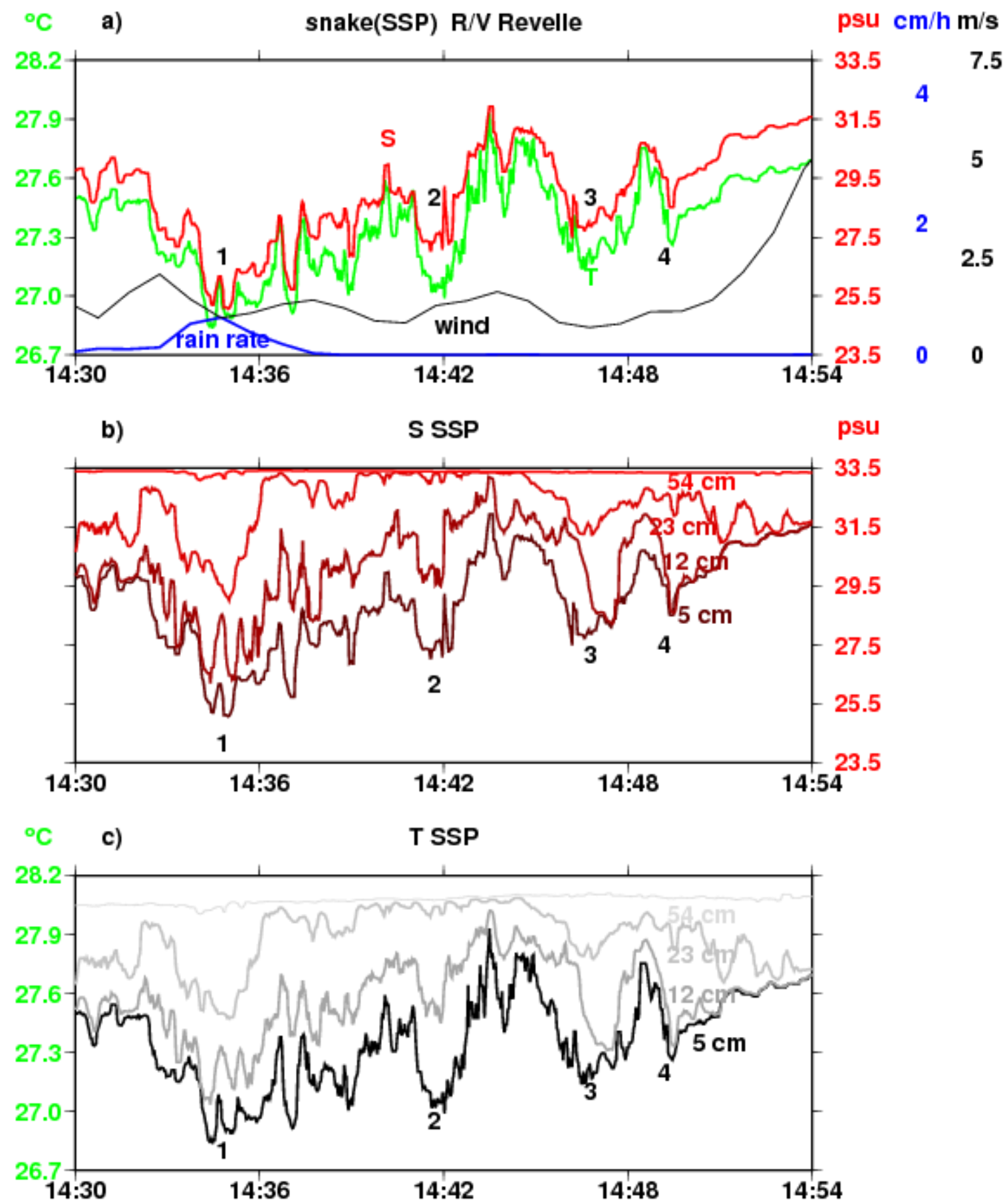

917 Figure 5: SSP data between 14:30 and 14;54. (5a) is a zoomed version of (3a)) and thus has 918 the same legend caption. (5b) and (5c) present the SSP 15-s median-filtered S and T data at 919 the different levels from $5-\mathrm{cm}$ to $53-\mathrm{cm}$ depth. The 5-cm level is from a pumped sea snake, 920 whereas the other levels are from instruments on the SSP's keel. Numbers 1 to 4 refer to 921 particular fresh/cool filaments crossed by the SSP. 


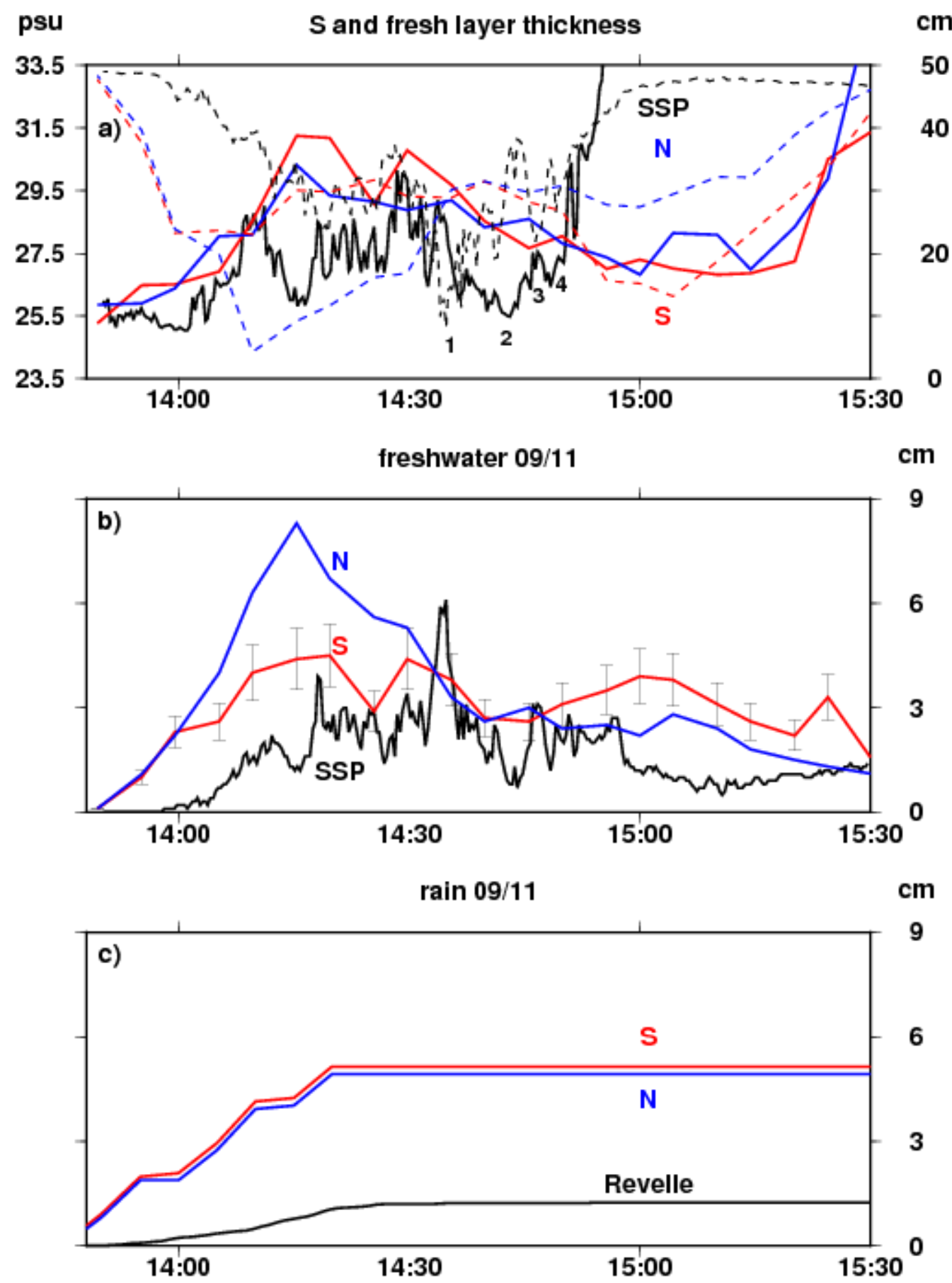

Figure 6: (a) Time series of penetration depth (full line) and $5 \mathrm{~cm}$ salinity (dashed lines) from

925 15-s median data from the SSP (black) and from the 5-minute sampled drifter time series

926 (blue and red lines, respectively, for drifter $\mathrm{N}$ and $\mathrm{S}$ ). The vertical scale of penetration depth is

927 only up to $50 \mathrm{~cm}$, to limit interpolation/extrapolation errors. (b) Vertically integrated

928 freshwater contents reported as equivalent rainfall amounts in $\mathrm{cm}$ for SSP (black) and drifters

$929 \mathrm{~N}$ (blue) and S (red; indicative 20\% error bars are also plotted). (c) Integrated rainfall amount

930 from R/V Revelle and from the SEA-POL 1-km resolution radar data interpolated to the

931 drifter locations. 
integrated temperature budget $09 / 11 \quad{ }^{\circ} \mathrm{C}^{\star} \mathrm{m}$

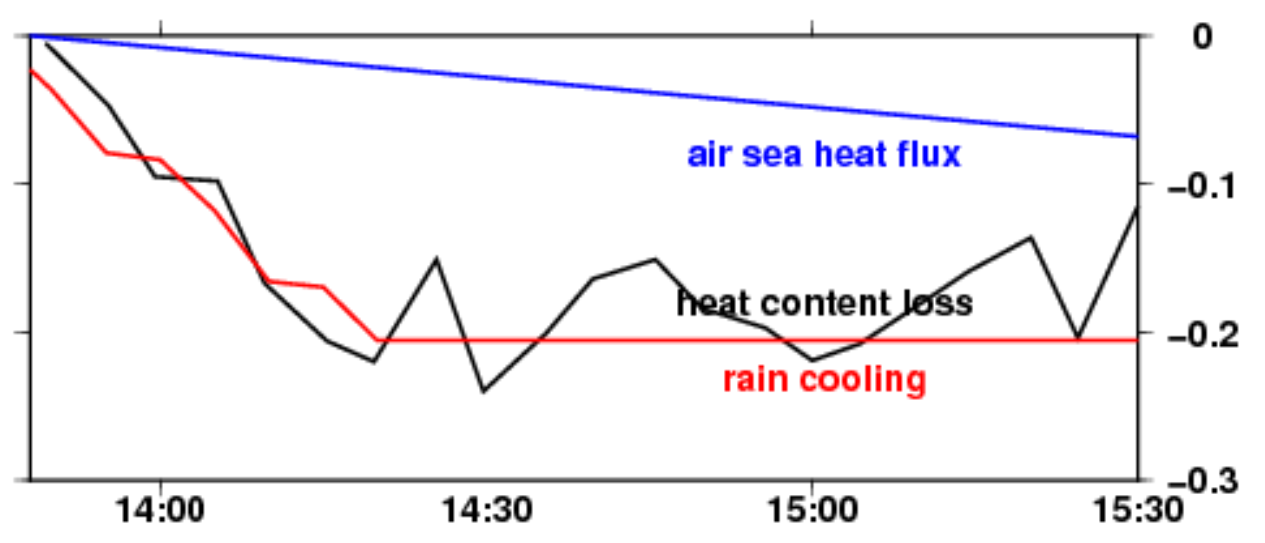

933

Figure 7: Vertically integrated temperature anomaly budget at SURPACT-S. The heat content

935 loss term is the measured integrated temperature anomaly, whereas no-rain heat flux (blue) is

936 based on the average net no-rain heat loss measured during the period by R/V Revelle, and

937 rain cooling (red) is estimated from the collocated radar rain rates, assuming a rain drop

938 temperature of $24^{\circ} \mathrm{C}$ (which optimizes the change observed until 14:20). 

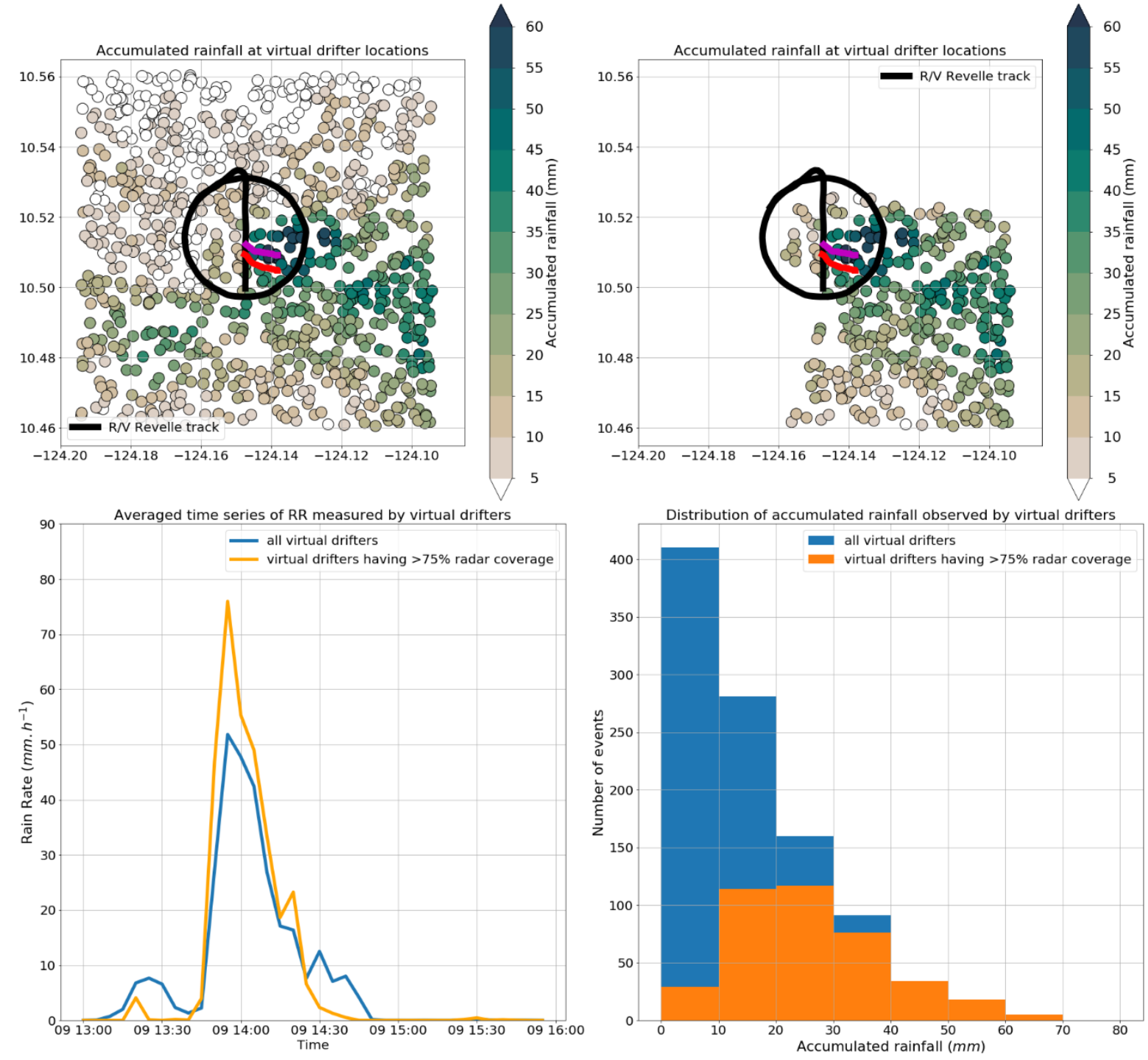

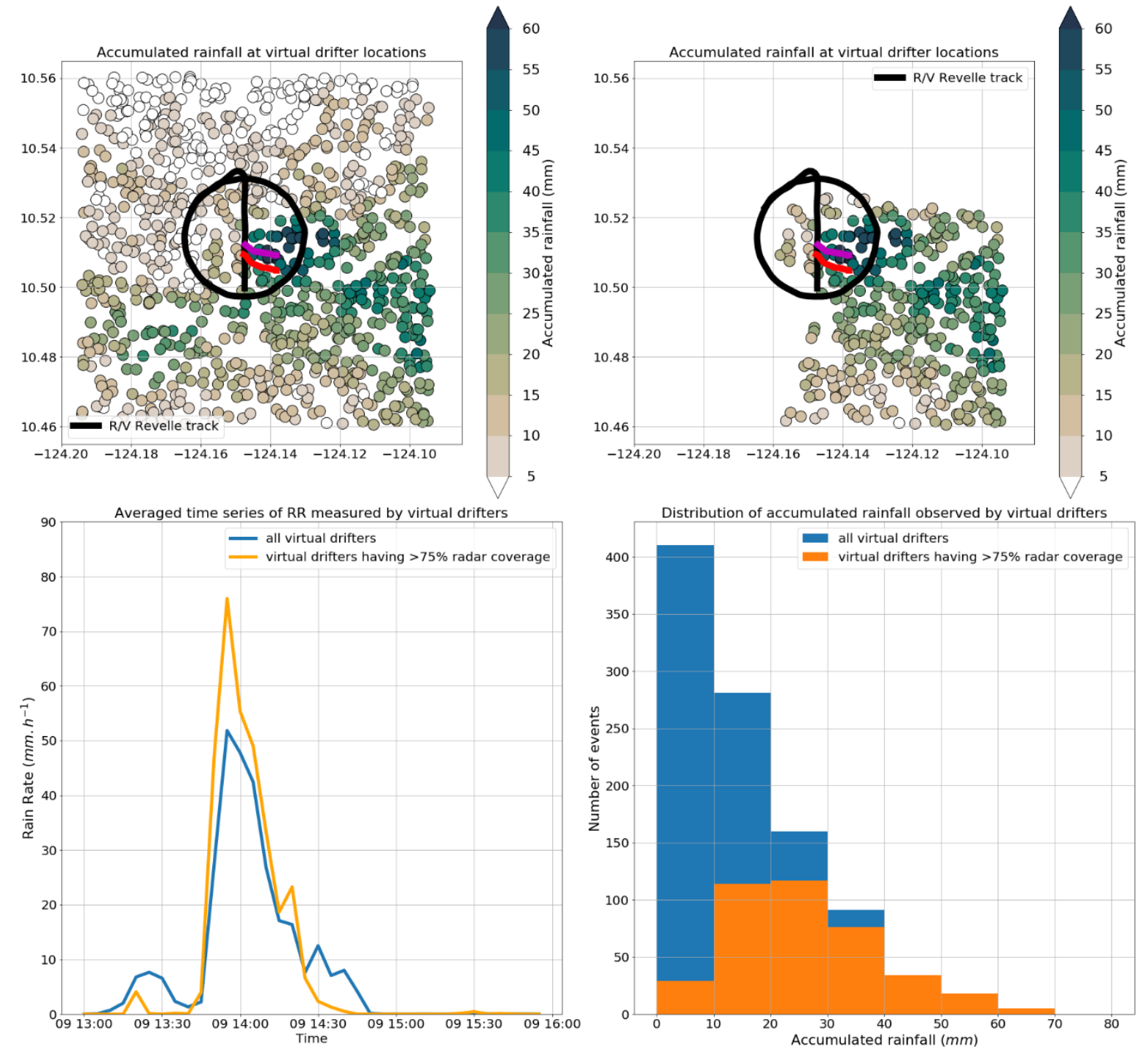

942 Figure 8: Statistics of rainfall at 1000 virtual drifters in a 10-km x 10-km square box. The

943 virtual drifters have the same trajectory as drifter $\mathrm{N}$, and rainfall is from SEA-POL radar rain 944 rate estimations between 13:30 and 14:45 UTC : Top, left) accumulated rainfall at the drifter 945 averaged positions; black line indicates the track of R/V Revelle during this time period;

946 magenta and red lines the trajectories of the two drifters; Top, right) accumulated rainfall only

947 for the 368 virtual drifters for which the SEA-POL radar provides rain rate information more

948 than $75 \%$ of the time; Bottom, left) Averaged time series of rain rate measured by virtual

949 drifters (blue, all drifters; orange, drifters with more than $75 \%$ of time coverage by the radar);

950 Bottom, right) histogram of accumulated rainfall among all the drifters (blue) and among the 951 drifters with more than $75 \%$ of time coverage by the radar (orange). 